Portland State University

PDXScholar

Spring 7-10-2014

\title{
Bumps along the long and winding road: Factors related to truck driver turnover and job-induced tension
}

Layla Rhiannon Mansfield

Portland State University

Follow this and additional works at: https://pdxscholar.library.pdx.edu/open_access_etds

Part of the Industrial and Organizational Psychology Commons, and the Organizational Behavior and Theory Commons

Let us know how access to this document benefits you.

\section{Recommended Citation}

Mansfield, Layla Rhiannon, "Bumps along the long and winding road: Factors related to truck driver turnover and job-induced tension" (2014). Dissertations and Theses. Paper 1874.

https://doi.org/10.15760/etd.1874

This Thesis is brought to you for free and open access. It has been accepted for inclusion in Dissertations and Theses by an authorized administrator of PDXScholar. Please contact us if we can make this document more accessible: pdxscholar@pdx.edu. 
Bumps along the Long and Winding Road:

Factors Related to Truck Driver Turnover and Job-Induced Tension

by

Layla Rhiannon Mansfield

A thesis submitted in partial fulfillment of the requirements for the degree of

\author{
Master of Science \\ in \\ Psychology
}
Thesis Committee:
Tayla Bauer, Chair
Berrin Erdogan
Ryan Olson
Donald Truxillo

\title{
Portland State University \\ 2014
}


(C) 2014 Layla Rhiannon Mansfield 


\title{
DRIVER TURNOVER AND JOB-INDUCED TENSION
}

\author{
Abstract \\ Voluntary turnover rates among truckload carriers are extremely high, ranging from 50\% \\ to more than $100 \%$ annually (Griffin \& Kalnbach, 2002), furthermore, long-haul truck \\ drivers operate in a stressor-filled environment, which exerts enormous adverse influence \\ not only their well-being but also on their intent to quit. This study explores the relational \\ aspects of the driver's work environment to highlight how the relationships that a driver \\ has with their organization, supervisor, and dispatcher can explain turnover and job- \\ induced tension. Drawing on Social Exchange Theory, Conservation of Resources \\ Theory, and concepts from Hirschman's (1970) theoretical framework of Exit, Voice, and \\ Loyalty, this study hypothesized that Perceived Organizational Support (POS) and \\ Leader-Member Exchange (LMX) have a negative relationship with turnover and job- \\ induced tension and that this relationship is moderated by the dispatchers' sensitivity to \\ voice. Further, this moderation was argued to be mediated by the dispatchers' \\ responsiveness. A modified model, that retains the original theoretical framework, was \\ tested after a number of measurement issues were uncovered. The modified model \\ collapses dispatcher sensitivity to voice and dispatcher responsiveness into one composite \\ variable, dispatcher communication effectiveness. Dispatcher communication \\ effectiveness was hypothesized to moderate the relationships between POS, LMX, \\ turnover, and job-induced tension. The hypotheses were tested in a sample of 166 truck \\ drivers and findings indicate the POS and LMX were directly related to job-induced \\ tension but these same predictor variables were unrelated to turnover. There was
}




\section{DRIVER TURNOVER AND JOB-INDUCED TENSION}

marginal support for the buffering effects of dispatcher communication effectiveness on the relationship between LMX and job-induced tension. These findings contribute to the knowledge about the role of POS and LMX on job-induced tension while uncovering the important dynamics in play between a driver and their dispatcher. The theoretical and practical implications of the study are discussed. 


\section{DRIVER TURNOVER AND JOB-INDUCED TENSION}

\section{Dedication}

This work is dedicated to Christina Journey. Thank you, mom, for everything. 


\section{DRIVER TURNOVER AND JOB-INDUCED TENSION}

\section{Acknowledgments}

I would like to thank Dr. Talya Bauer for her support and encouragement during this project. I would also like to acknowledge my committee members for their insight and feedback, I am grateful. 


\section{DRIVER TURNOVER AND JOB-INDUCED TENSION}

Table of Contents

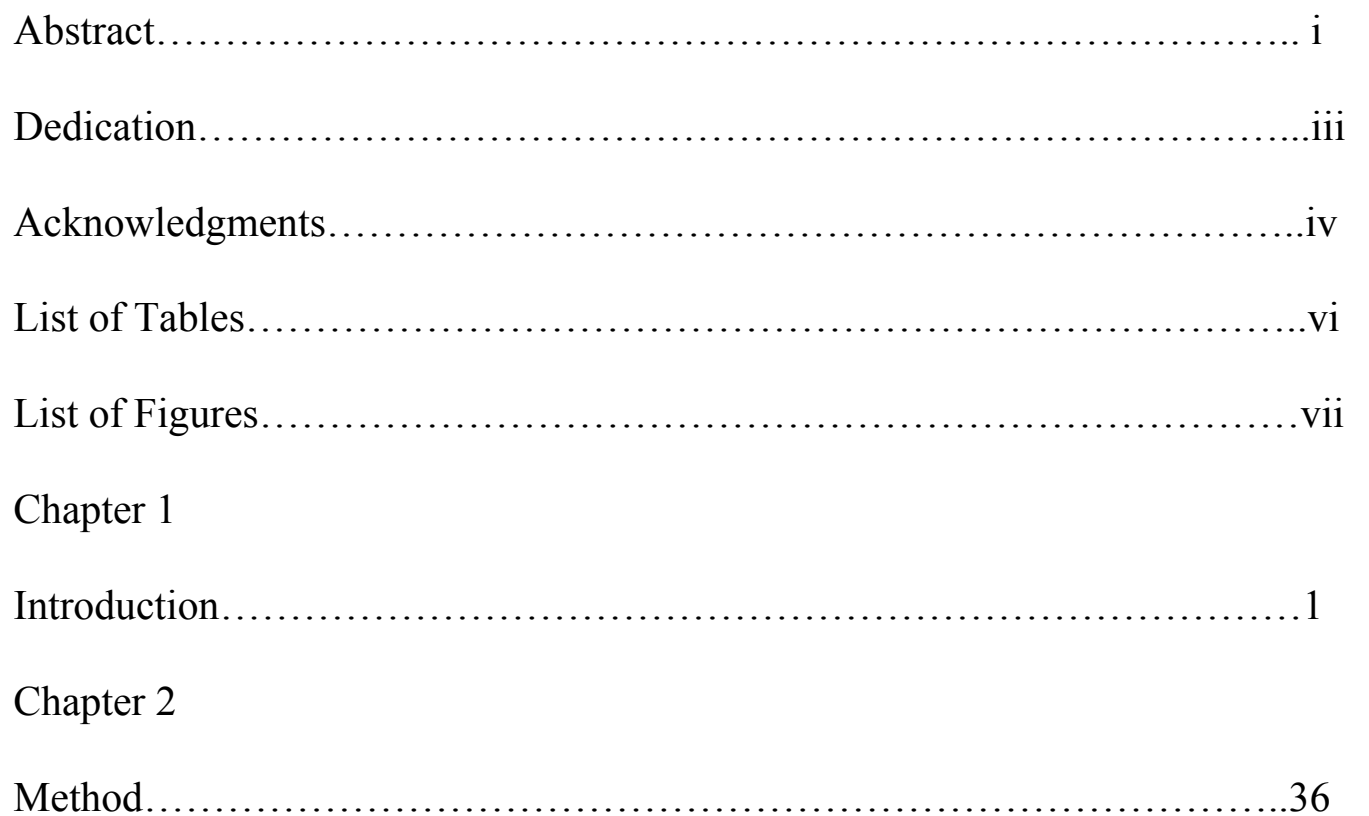

Chapter 3

Results.......................................................44

Chapter 4

Discussion......................................................51

References.....................................................86

Appendix A

Items for the composite variable dispatcher communication effectiveness.....110

Appendix B

Survey Items.................................................111 


\title{
DRIVER TURNOVER AND JOB-INDUCED TENSION
}

\author{
List of Tables
}

Table 1

Means, Standard Deviations, and Intercorrelations among Study Variables........68

Table 2

Summary of Study Changes and Overview of the Results of the Hypotheses.........70

Table 3

Logistic Regression Analyses for Predicting Turnover with POS and LMX.........71

Table 4

Logistic Regression Analysis for Predicting Employee Turnover with the Interaction of POS and Dispatcher Communication Effectiveness............................72

Table 5

Logistic Regression Analysis for Predicting Employee Turnover with the Interaction of LMX and Dispatcher Communication Effectiveness..........................73

Table 6

Hierarchal Multiple Regression Analyses Predicting Job Tension from POS

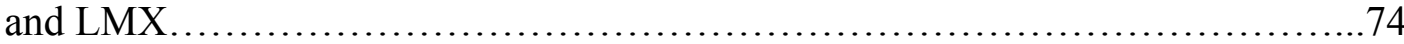

Table 7

Hierarchal Multiple Regression Analysis for Predicting Job Tension with the Interaction of POS and Dispatcher Communication Effectiveness......................... 75

Table 8

Hierarchal Multiple Regression Analysis for Predicting Job Tension with the Interaction of LMX and Dispatcher Communication Effectiveness. .76 


\title{
DRIVER TURNOVER AND JOB-INDUCED TENSION
}

\author{
List of Figures
}

Figure 1

Conceptual Model...................................................77

Figure 2

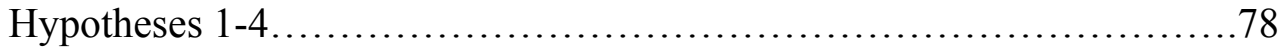

Figure 3

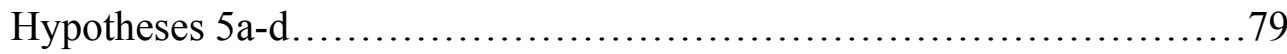

Figure 4

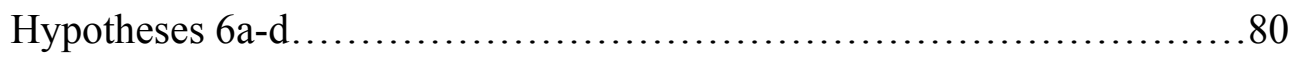

Figure 5

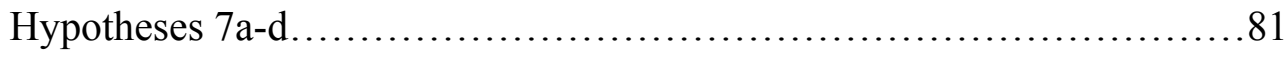

Figure 6

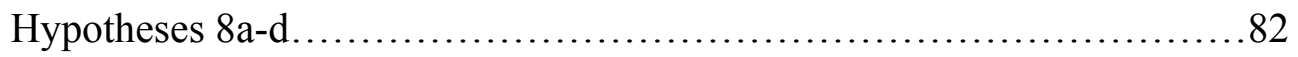

Figure 7

Modified Model for Hypotheses 5 and 6 to Reflect Composite Variable Dispatcher

Communication Effectiveness....................................83

Figure 8

Modified Model for Hypotheses 7 and 8 to Reflect Composite Variable Dispatcher

Communication Effectiveness...................................84

Figure 9

Interaction be5tween LMX and Dispatcher Communication Effectiveness on Job-induced Tension. 85 


\section{DRIVER TURNOVER AND JOB-INDUCED TENSION}

\section{Chapter 1 Introduction}

In 2009 , nearly $70 \%$ of all US freight traveled on a truck at some point, with three million drivers hauling 9.1 billion tons of material (American Trucking Associations [ATA], 2012). However, the efficiency and safety of this critical industry is threatened by a growing, chronic driver shortage that is exacerbated by high turnover rates. Voluntary turnover rates among truckload carriers are extremely high, ranging from $50 \%$ to more than $100 \%$ annually (Griffin \& Kalnbach, 2002). Such turnover rates are economically costly and potentially dangerous. Research shows that drivers who turn over frequently (measured as 3 or more job changes in a two-year period) have more than double the crash rate of drivers who make fewer job changes (Federal Motor Carrier Safety Administration, 2003). Furthermore, the average replacement cost per driver has been approximated at $\$ 8,234$ with some estimates that the cost could exceed $\$ 20,000$ (Rodriguez, Kosir, Lantz, Griffin, \& Glatt, 2000; Whitaker, 2010).

Research examining turnover in the trucking industry has focused on factors such as driver's pay, time spent from home (Ozment \& Keller, 1999) benefit plans, training, and electronic surveillance systems (Shaw, Delery, Jenkins, \& Gupta, 1998) and while these are probable determinants to driver turnover, they do not explain the "churning" of drivers. That is, focusing on the characteristics of the job does not explain why some drivers move from one organization to another with equal pay, benefit plans, and time from home. With an industry shortage of qualified drivers, it is of interest to design 


\section{DRIVER TURNOVER AND JOB-INDUCED TENSION}

strategies to maximize the satisfaction of qualified drivers. Building on previous research examining relational predictors of turnover in the truck driving industry (i.e., dispatcher responsiveness; Keller \& Ozment, 1999a, 1999b) this study explores the role social exchange relationships have in determining driver job-induced tension and turnover. Therefore, the purpose of this study is two-fold. First, it is the premise of this study that a driver's relationship with others in the organization may help explain why drivers leave one organization for another. To illuminate this premise I will build upon, and extend, what we already know about the relationship of Leader-Member Exchange (LMX) and Perceived Organizational Support (POS) with turnover within a truck driver context.

Second, this study examines the relationships between LMX and POS on a driver's job-induced tension. Long-haul trucking has been classified as one of the highest risk occupations in the United States (Bureau of Labor Statistics, 2012). Truckers regularly experience high levels of occupational stress (Essenberg, 2003; Saltzman \& Belzer, 2007) that places them at risk for psychological and social problems such as depression (da Silva, de Pinho, de Mello, de Bruin, \& de Bruin, 2009), substance abuse (Anderson \& Riley, 2008), and risky sexual behaviors (Apostolopoulos et al., 2009). Job induced tension is the result of an employee's general feeling of anxiety or apprehension about their work which manifests in the form of poor physical health and well-being (Speilberger, Gorsuch, Lushene, Vagg, \& Jacobs, 1983). Research has focused on the safety and well-being of truck drivers but very few studies have examined the role of organizational relationships as predictors of job-induced tension (e.g., de Croon, Blonk, 


\section{DRIVER TURNOVER AND JOB-INDUCED TENSION}

de Zwart, Frings-Dresen, \& Broersen, 2002) and none have examined to role of POS and LMX. This study attempts to fill this gap. In sum, the focus of this study is on the workrelated relationships that drivers have with other organizational members that may impact the outcomes of turnover and job-induced tension.

Taking a relational perspective in this context contributes to the existing literature in three specific ways. First, as mentioned, this study contributes to the robust knowledge of POS and LMX on turnover and job-induced tension in a truck-driving context that is traditionally treated as devoid of relationships. Second, this study highlights the important role of dispatchers as those organizational agents who have the opportunity to reduce job-induced tension and the ability to halt the exodus of drivers by remaining sensitive to driver concerns and driver voice. The research on driver retention finds that driver attitudes toward dispatchers can play an important part in driver satisfaction (Richard, LeMay, \& Taylor, 1995) and turnover (Keller \& Ozment 1999b) yet this research is relatively rare. This study expands our understanding of the dispatcher/driver relationship. Third, by highlighting the relational aspects of organizational life this study has the potential to explain why drivers leave one trucking company for another. It is the premise of this study that the relationships the driver forms with their organization, supervisor, and dispatcher are key predictors of turnover and job-induced tension. To begin, I describe my conceptual model (see Figure 1). I then define and describe each of the constructs under examination as well as theoretically weave these constructs together. Next, I describe my method, analyses, results, and finally, I conclude with a discussion of 


\section{DRIVER TURNOVER AND JOB-INDUCED TENSION}

my findings, and the potential implications and limitations of my study.

\section{Conceptual Model Overview}

Rooted within a Social Exchange Theory (SET) framework, the two independent variables in this study are POS and LMX. POS is the perception that the organization values and cares about an employee's well-being (Eisenberger, Huntington, Hutchison, \& Sowa, 1986). As seen in Figure 1, POS is one of two key antecedents in my study. POS is defined as a quality-focused reciprocal social exchange relationship between the employer and employee. For example, when an employer is supportive, employees are more likely to reciprocate with increased commitment to the organization. Furthermore, an employee who perceives support is likely to want to give back to the organization and work hard to preserve this resource. This study identifies POS as a job resource that can quell turnover as well as protect drivers from job-induced tension. Aligned with this reasoning I maintain that POS will be negatively related to turnover, and job-induced tension.

Also as seen in Figure 1, another important factor in the breakdown of the employee-organization relationship is the quality of the interactions between employees and their immediate supervisors. LMX theory posits that the relationship between a supervisor and an employee develops as a result of work-related exchanges between these two individuals. Achieving good relations between supervisors and subordinates helps to embed employees within organizations, and thereby provides a disincentive for employees to quit. Furthermore, a good quality exchange with one's supervisor is another 


\section{DRIVER TURNOVER AND JOB-INDUCED TENSION}

job resource for employees to pull from when faced with work stress. Thus, I further propose that LMX quality will be negatively related to turnover and job-induced tension.

Although a driver's relationship with their supervisor is a key component through which to understand driver turnover and job-induced tension, a driver's dispatcher plays a very important and unique role in their organizational life. This study emphasizes that the effectiveness of dispatcher communication can provide a buffer to the proposed negative relationships stated above. Sensitivity to voice is an attitude held by dispatchers to show concern and good listening skills. Therefore, a dispatcher's sensitivity to driver voice will moderate the relationships between POS, LMX, turnover, and job-induced tension. Responsiveness is a behavioral component of sensitivity to voice and indicates those dispatchers that effectively address their drivers' concerns. Thus, this study hypothesizes that the moderating effect of sensitivity to voice will be mediated by a dispatcher's responsiveness to the driver's voice.

This study's two dependent variables, turnover and job-induced tension, were selected based on the context in which the data were collected. As mentioned above, turnover is critical problem in the trucking industry. Furthermore, the well-being of drivers is of utmost concern due to the dangerous job conditions and health concerns associated with the job (Olson, Anger, Elliot, Wipfli, \& Gray, 2009) In the next two sections, I will review and discuss these important and relevant outcome variables.

\section{Turnover}

Turnover is one of the most vibrant areas of research within the 


\section{DRIVER TURNOVER AND JOB-INDUCED TENSION}

Industrial/Organizational Psychology and Organizational Behavior domains with more than 1,500 academic studies on the subject (Barrick \& Zimmerman, 2005; Holtom, Mitchell, Lee, \& Eberly, 2008). There have been a number of literature reviews on the topic (e.g., Griffeth, Hom, \& Gaertner, 2000; Holtom et al., 2008; Hom \& Griffeth, 1995; Maertz \& Campion, 1998) signifying the depth and span of previous turnover research.

There are many types of turnover: voluntary, involuntary, layoffs, and retirement. Voluntary turnover is defined as choosing to leave an organization, whereas involuntary turnover refers to when a person is asked to leave an organization. Layoffs refer to organizational changes which require terminating employees, and retirement is when employees leave an organization and cease to work because they have reached a certain age. In the past, turnover was considered a result of negative job attitudes. In 1958, March and Simon published their book Organizations which emphasized two factors that are predictive of an employee's turnover intent, perceived desirability and perceived ease of leaving the organization; today these concepts are typically labeled as job satisfaction and perceived alternatives.

The decision path model developed by Lee and Mitchell (1994) takes a different perspective and suggests that turnover is predicted by the presence of a shock, which changes the reasons employees leave organizations. Shocks are operationalized as jolting events, which begin the thought process of an employee on whether or not to leave an organization (Lee \& Maurer, 1997). More specifically, this model states that there is an initiating event (shock or no shock) and then a cognitive or emotional process, which 


\section{DRIVER TURNOVER AND JOB-INDUCED TENSION}

leads to search behavior (present or not present) and the decision to quit (automatic, fairly automatic, or deliberate). The different paths also lead to different amounts of time in which it takes employees to make a decision to leave an organization. Lee and Maurer (1997) found that employees were more likely to leave due to shock than lack of job satisfaction.

Introduced by Mitchell, Holtom, Lee, Sablynski, and Erez (2001), job embeddedness is a relatively new construct when compared to traditional constructs in the turnover literature that focus on job attitudes (i.e., organizational commitment, job satisfaction). Job embeddedness can be thought of as the sum of all factors that influence a worker's retention and examine the kinds of relationships that bind an employee to an organization. At its core, job embeddedness is composed of three key aspects: links, fit, and sacrifice. The first aspect, links, refers to the connections (both formal and informal) that an employee has to other people or institutions in the organization or community (Burton, Holtom, Sablynski, Mitchell, \& Lee, 2010; Mitchell et al., 2001). The second aspect, fit, is described as an employee's perceived compatibility with their organization or community (Burton et al., 2010; Mitchell et al., 2001). The final aspect of job embeddedness, sacrifice, refers to the perceived tangible and psychological losses associated with quitting a job (Mitchell et al., 2001). The notion behind this aspect is that the more an employee would lose upon leaving their current job, the less likely they are to quit. Just like the other aspects of the job embeddedness construct, sacrifice refers to both on the job losses as well as off the job losses. For example, over a period of time a 


\section{DRIVER TURNOVER AND JOB-INDUCED TENSION}

worker may have accrued any number of work-related benefits such as pension plans, close friendships, and tenure. Deciding to leave an organization could potentially put all of these things in jeopardy.

Turnover and truck drivers. The reviewed models above signify the evolution of the study of turnover. March and Simon (1958) focused on an attitudinal approach to understanding turnover, while Lee and Maurer (1997) found that shocks were more predictive than attitudes. Finally, Mitchell and colleagues developed a model that encapsulates both off the job and on the job factors that influence turnover. These models provide a guiding framework though which to understand driver turnover.

There are a number of studies examining voluntary turnover among truck drivers. These studies have found a variety of determining factors involved when predicting turnover, including age, seniority, education and compensation (Beilock \& Capelle, 1990), salary and benefits (Min \& Lambert, 2002; Stephenson \& Fox, 1996), recognition and job value (Stephenson \& Fox, 1996), restricted latitude in decision making (de Croon, Sluiter, Blonk, Broersen, \& Frings-Dresen, 2004), as well as electronic surveillance and monitoring policies (Shaw et al., 1998). Furthermore, Suzuki, Crum, and Pautsch (2009) found that the very nature of haulage operations itself (i.e., type of freight, distance travelled, rest time, waiting time, weekend shifts, mileage rates) is also seen as an important determinant of turnover. A few studies have identified the role of the dispatcher as a key factor in driver turnover (Keller \& Ozment, 1999a, 1999b; Keller, 2002; Min \& Lambert, 2002; Morrow, Suzuki, Crum, Ruben, \& Pautsch, 2005; Paillé, 


\section{DRIVER TURNOVER AND JOB-INDUCED TENSION}

Fournier, \& Lamontagne, 2011; Richard et al., 1995; Stephenson \& Fox, 1996). This body of research suggests that the dispatcher plays an important role in determining a driver's turnover behavior. For example Keller and Ozment (1999a) showed that dispatchers, who exercise greater sensitivity and responsiveness when communicating with drivers, have a better chance of retaining their drivers. The entire focus of their study pertained to the relationship dynamics within the firm with the goal of reducing driver turnover. Building on this research this study will also argue that sensitivity and response to drivers' concerns is linked to voluntary turnover. That is, dispatchers with good listening skills who effectively address their drivers' concerns could help reduce driver turnover more than those who fail to recognize the importance of empathic communication. This study moves beyond the Keller and Ozment (1999a) study to explore how dispatcher sensitivity and responsiveness can act as a buffer when social exchange relationships are weak.

\section{Job-Induced Tension}

Stress is generally defined as a measure of pressure, suffering, or physiological hardships that arise when demanding events or conditions, otherwise known as stressors, negatively affect one's facility to manage a situation or situations (Cooper \& Dewe, 2004; Lazarus \& Folkman, 1984). Workplace stress can manifest itself among employees through many facets. For example, individuals in a stressful work environment within an organization may be more susceptible than individuals in a relatively less stressful work environment to physiological ailments, such as heart disease (including high blood 


\section{DRIVER TURNOVER AND JOB-INDUCED TENSION}

pressure and cardiovascular disease), ulcers, chronic pain, as well as psychological disorders such as anxiety, depression, and frustration (Jex \& Beehr, 1991; Parasuraman, Grennhaus, \& Granrose, 1984). Job tension is defined as stress arising from work-related experiences (Kahn, Wolfe, Quinn, \& Snoek, 1992) and is commonly measured with the job tension scale developed by House and Rizzo (1972) as it is in this study.

Job-induced tension and drivers. Drivers face a multitude of interconnected workplace stressors. The conditions of a driver's job, such as the long hours of driving, the loading and unloading cargo, the irregular schedules and the high work-life conflicts have been found to be associated with work-related injury and poor health status (Apostolopoulos, Peachey, \& Sönmez, 2011; Apostolopoulos, Sönmez, Shattell, Gonzales, \& Fehrenbacher, 2013). These work conditions have the potential to adversely impact and exacerbate the health of truck drivers. For example, combined work stressors (e.g., long work hours) and lifestyle factors (e.g., sedentary lives) are closely linked to the trucking work environment, which essentially burdens truckers with a unique constellation of CVD risk factors (Robinson \& Burnett, 2005). Furthermore, the safety of drivers is exacerbated by paid-by-the-mile compensation that encourages drivers to use excessive driving speed and working while fatigued (Wright \& Quinlan, 2008).

According to Apostolopoulos and colleagues (2013) in 2008 almost two million truckers either experienced a near miss or actually crashed, causing death or injury to thousands. In sum, drivers face a variety of workplace stressors that have the potential to increase their job-induced tension. The previous sections discussed the what of my model. The 


\section{DRIVER TURNOVER AND JOB-INDUCED TENSION}

next sections will provide the why or theoretical framework that will link these critical outcome variables with the independent variables in this study.

\section{Theoretical Framework and Hypothesis Development}

Social exchange theory (SET) was selected as one of the theoretical frameworks in this study because it is one of the most influential frameworks in our understanding of workplace behaviors. Theories within SET framework (e.g., equity theory, Adams, 1963; Thibaut \& Kelley's theory of interdependence, 1959) have provided the foundations for theories on a variety of diverse organizational phenomenon, such as organizational justice (e.g., Masterson, 2001; Rupp \& Cropanzano, 2002), safety-related behavior (e.g., Hofmann \& Morgeson, 1999), leadership (e.g., Graen \& Uhl-Bien, 1995), and psychological contracts (Dabos \& Rousseau, 2004).

In SET, social exchange refers to a series of interactions between two parties such as supervisor and subordinate, employee and organization, coworkers, and employee and customer. Over time through the interactions, the two parties develop a relationship, defined as interpersonal connection or attachment, which is distinct from the interactions.

For specific interactions or the series of interactions, there are exchange rules followed by the two exchange parties, such as reciprocity (Gouldner, 1960), negotiated agreements (Molm, 2001, 2003), altruism, group gain, status consistency, competition, and rationality (Meeker, 1971). In SET, reciprocity is usually considered as an exchange rule explicitly or implicitly adopted by two exchange parties. Exchange parties following the reciprocity rule transmit resources to each other contingently (Emerson, 1976). 


\section{DRIVER TURNOVER AND JOB-INDUCED TENSION}

Thibault and Kelley's (1959) interdependence theory described that the pattern of exchange follows a sequence in which one side provides one type of benefit and the other side returns some benefit.

Social exchanges, intended to maximize benefits and minimize costs, may take many different forms. The benefits or resources exchanged may be concrete (having objective value) or symbolic (having meaning beyond objective value). Foa and Foa's $(1974,1980)$ resource theory suggests six types of resources that are offered for exchange: love, status, information, money, goods, and services. Exchange resources may be characterized by their universalism or particularism. A resource is considered high in universalism when its worth is independent of the source. For example, the monetary value of currency is constant regardless of who provides it. In contrast, love is highly particularistic, and its worth is largely dependent upon who offers it.

Socioemotional need also determines the worth of the resource. Gouldner (1960) asserted, "the value of the benefit [received from others] and hence the debt is in proportion to and varies with - among other things - the intensity of the recipient's need at the time the benefit was bestowed" (p. 171). Rhoades and Eisenberger (2002) asserted that the resources received from another person or organization are more highly valued if they are deemed to be given voluntarily rather than involuntarily.

In the leadership literature, theories on the mechanisms underlying the effect of exchange relationship on employees' attitudes and behaviors (e.g., LMX subordinates' outcomes) often argue that one party feels the obligation to reciprocate to the other. For 


\section{DRIVER TURNOVER AND JOB-INDUCED TENSION}

example, it is argued that subordinates feel the obligation to reciprocate to their supervisors; thereby they hold more positive attitudes and perform better (Dulebohn, Bommer, Liden, Brouer, \& Ferris, 2012; Gerstner \& Day, 1997; Hofmann, Morgeson, \& Gerras, 2003).

A relationship and an exchange may be related but are distinctive from each other. A relationship is the interpersonal connection or attachment developed from exchanges. In the workplace, employees can develop relationships with coworkers, supervisors, and the organization as they engage in social exchanges. The quality of exchange relationship can be indicated by the level of mutual trust, respect, obligation, and communality of goals shared by the exchange parties.

SET theory argues that the exchange process can influence the relationship developed and the maintenance of the relationship; and it is possible that the characters of exchange relationship in turn affect the process of exchanges (Blau, 1964; Cropanzano \& Mitchell, 2005). By separating the relationship constructs from the exchanges, it can help us clarify the mechanisms underlying the influence of social exchange on exchange parties. Two such relationship constructs are POS and LMX (see sections below).

\section{Conservation of Resources}

Hobfoll's (1989) conservation of resources (COR) theory will form the theoretical basis for the hypotheses related to job-induced tension. At the center of COR is the notion that individuals seek to acquire, maintain, and protect the things that they value (Grandey \& Cropanzano, 1999) and that the loss of these resources is the principal catalyst for the 


\section{DRIVER TURNOVER AND JOB-INDUCED TENSION}

stress process (Hobfoll, 2001). The basic premise is that people have an innate as well as a learned desire to conserve the quality and quantity of their resources and to limit any state that might jeopardize the security of these resources (Hobfoll, 1989). The theory is based on the general principle of minimization of loss and maximization of gain.

Resources are generally objectively determined (Hobfoll, 2001) and may include objects, personal characteristics, conditions, or energies that are valued by an individual (Lapierre \& Allen, 2006). Stress results when individuals are threatened with a loss of resources, when individuals experience an actual loss of resources, and when an expected resource gain is not actualized (Hobfoll, 2001; Premeaux, Adkins, \& Mossholder, 2007). The model notes that while an individual might be the focus of the research on resources, it is the environmental circumstances that provide the threat to an individual's resources. In the context of this study, I argue that the environmental circumstances are the job of a driver and its inherent dangerous job conditions.

In COR theory, social relations are seen as a resource to the extent that they provide or facilitate the preservation of valued resources. Although COR is conceived as a general motivation theory (Hobfoll, 1989), whereby the accumulation, protection, and allocation of resources acts to energize, direct, and sustain behavior, the theory has often been applied to stress (Halbesleben, 2006; Harvey, Harris, Harris, \& Wheeler, 2007) as well as to other relationships found in the organizational context such as age and perceptions of organizational politics (Treadway, Ferris, Hochwarter, Perrewé, Witt, \& Goodman, 2005) and emotional exhaustion and performance (Wright \& Cropanzano, 


\section{DRIVER TURNOVER AND JOB-INDUCED TENSION}

1998).

COR theory has also been applied in studies that mirror this one. For example, Jawahar, Stone, and Kisamore (2007) argue within a COR framework that POS is a form of support that buffers the impact of role conflict and burnout. Furthermore, Harris, Wheeler, and Kacmar (2011) utilize COR theory to support their finding that LMX leads to organizational embeddedness, which in turn mediates the relationship between job satisfaction, turnover intentions, and turnover. Finally, in a study of health care workers Thomas and Lankau (2009) describe LMX as a form of social support that minimizes emotional exhaustion by decreasing role stress. This study also utilizes COR theory to explain how higher levels of POS and better quality LMX relationships serve as resources and impact job-induced tension. That is, whereas the benefits received as the result of an exchange of resources inherent in high POS and higher quality LMX relationships can lead to resource gain the converse is true as well. The lack of resources exchanged in low POS contexts and lower quality LMX relationships will result in resource loss, which in turn adds to one's job-induced tension.

The previous discussion serves to provide the theoretical lens through which to view this study's main proposition, that is, that taking a relational perspective can provide important clues to driver turnover and job-induced tension. In the next section, I define and discuss the independent variables under review as well as propose this study's hypotheses.

\section{Perceived Organizational Support}




\section{DRIVER TURNOVER AND JOB-INDUCED TENSION}

Organizational support theory "assumes employees form general beliefs concerning how much the organization values their contributions and cares about their well-being” (Eisenberger, Armeli, Rexwinkel, Lynch, \& Rhoades, 2001, p. 42).

Furthermore, employees tend to personify the organization, assigning humanlike characteristics to the organization as a whole (Rhoades \& Eisenberger, 2002).

Eisenberger et al. (1986) conducted a series of three studies on perceived organizational support, absenteeism, and social exchange ideology. Eisenberger and his colleagues demonstrated that a) employees form global beliefs about the extent to which their company values them and their contributions, b) higher levels of perceived organizational support reduces absenteeism, and c) the correlation between POS and absenteeism was stronger among employees who held a high social exchange ideology, lending support to organizational support theory.

POS and turnover. Based largely on SET, Eisenberger and his colleagues maintain that high levels of POS create feelings of obligation to repay the organization for the goodwill it expends through increased effort and commitment to the organization (Eisenberger et al., 1986; Eisenberger et al., 1997; Rhoades \& Eisenberger, 2002). According to Eisenberger, Cummings, Armeli, and Lynch (1997), POS “...would a) meet needs for approval, esteem, and social identity, and b) produce the expectation that superior conventional performance and extra-role behavior, carried out for the organization, will be recognized and rewarded." (p. 812). Further, the norm of reciprocity (Gouldner, 1960) suggests that individuals have the responsibility to react positively to 


\section{DRIVER TURNOVER AND JOB-INDUCED TENSION}

favorable treatment. This exchange assumes that both employers and employees will consider the needs and desires of the other when actions are undertaken. Continued reciprocity over an extended period of time would likely strengthen the bond between employer and employee.

Critical to the maintenance of this association is the continuance of a mutually beneficial relationship between employer and employee. Therefore, researchers have focused significant attention to POS as a key predictor of turnover intentions (e.g., Maertz, Griffeth, Campbell, \& Allen, 2007). High levels of POS create feelings of obligation in which employees reciprocate with increased commitment, loyalty, and performance (Rhoades \& Eisenberger, 2002). In support of this assertion a number of empirical studies have examined POS and its relationship with turnover intentions.

Less examined is the relationship between POS and turnover. Most recently, Allen and Shanock (2013) examined 500 newcomers to find that POS mediated the relationship between socialization tactics and voluntary turnover. Furthermore, Allen, Shore, and Griffeth's (2003) work on POS and human resource practices introduced a model examining antecedents of POS and the role of POS in predicting turnover. Findings revealed that the employees' perceptions of supportive human resources practices (fairness of rewards, growth opportunities, and participation in decision making) contributed to POS development and that POS was negatively related to withdrawal in the turnover process. Finally, in their meta-analysis, Rhoades and Eisenberger (2002) found a mean corrected correlation of -.51 between POS and turnover 


\section{DRIVER TURNOVER AND JOB-INDUCED TENSION}

intention $(k=14)$, and a mean corrected correlation of $-.11(k=6)$ between POS and turnover behavior. These studies illustrate that to the extent that employees infer that the organization does not value them nor cares for their well-being, it is expected that employees are less committed to the organization and more likely to turn over. This established effect of POS on turnover has yet to be tested in a trucking industry context therefore this study attempts to fill this gap by replicating this finding in the lone worker context.

Hypothesis 1: POS will be negatively related to turnover.

Armeli, Eisenberger, Fasolo, and Lynch (1998) suggested that perceived organizational support meets a variety of socioemotional needs within the employer/employee relationship. The need for esteem may be satisfied as the employee infers that the organization considers them valuable and is proud of his or her accomplishments. When the employee perceives organizational support and feels that the organization is committed to them and accepts them, the need to belong may be satisfied. Emotional safety and support needs are satisfied as the employee perceives that the organization will provide understanding and aid to deal with stressful situations at work and home.

POS and job-induced tension. In his COR theory, Hobfoll $(1989,2001)$ defined resources as “... those objects, personal characteristics, conditions, or energies that are valued by the individual or that serve as a means for attainment of these objects, personal characteristics, conditions, or energies" (Hobfoll, 1989, p. 516). COR theory (Hobfoll, 


\section{DRIVER TURNOVER AND JOB-INDUCED TENSION}

$1989,2001)$ posits that people are intrinsically motivated to obtain, retain, and protect these resources. As mentioned previously, the COR model proposes that stress is the result of a threat to resources (e.g., the perception that one might lose his or her job), the actual loss of a resource (e.g., the loss of the job), or the insufficient gain of additional resources following significant investment of resources (e.g., the inability to obtain employment following the resources invested obtaining a college degree). In a work context, the stress caused by one of the three paths will lead employees to experience jobinduced tension over time, particularly because the rate that work demands use up employee resources is typically greater than the rate with which resources are replenished (Freedy \& Hobfoll, 1994).

Truck drivers constitute an occupational group that is regularly exposed to night work, insufficient sleep, job strain, and elevated stress (de Croon et al., 2002; Horne \& Reyner, 1999; Moreno et al., 2004) resulting from high levels of noise and vibration during driving, in combination with pressure to deliver goods on time and the physical demands of extended hours driving in a seated position (Horne \& Reyner, 1999). Driving at night, in particular, and for extended hours has been shown to result in sleep deprivation, sleepiness, and increased risk of traffic accidents (de Pinho et al., 2006), putting this population at a considerable health risk due to the increased work demands of the occupation. In addition, the work conditions of truck drivers have been proposed to lead to an unhealthy lifestyle with high alcohol intake, cigarette smoking, and poor physical activity (Moreno et al., 2004). Thus drivers may be at an increased risk of 


\section{DRIVER TURNOVER AND JOB-INDUCED TENSION}

resource loss.

POS is a global attribution about whether the organization values their contributions and cares for their well-being. Due to the increased risk faced by drivers the extent that the drivers feel as if the organization cares for their well-being may mitigate the impact of job-induced tension. POS should signal to employees that emotional and tangible support is there if needed. In a recent review Baran, Shanock, and Miller (2012) indicate that a current theme in the POS literature is the examination of its relationship with employee well-being indicating the importance of POS on job-induced tension. In fact, recent empirical studies have shown that POS increases overall levels of improved general health (Bradley and Cartwright, 2002), decreases somatic complaints (Dupre'\& Day 2007), and burnout (Kang, Twigg, \& Hertzman, 2010). Thus, POS appears to have a direct effect on employee well-being. It is likely that POS is contributing to greater physical and psychological well-being because the socioemotional support function of POS meets needs for esteem, affiliation, and emotional support.

Taken together and utilizing a COR framework I propose that POS fulfills socioemotional needs and thus represents a resource. To the extent this resource is not available, it is expected that there will be an increase in job-induced tension. Evidence supports this notion as found by a study by Jones, Flynn, and Kelloway (1995). These authors examined the relationship between POS and work stress, satisfaction, and commitment in a sample of employees from three workforces: manufacturing, Canadian Federal Public Service, and special-educational needs assessment. Their results revealed 


\section{DRIVER TURNOVER AND JOB-INDUCED TENSION}

a strong correlation between POS and work stress $(r=-.59 ; p<.01)$. Therefore, the current study posits that higher levels of POS will lead to lower levels of job-induced tension.

Hypothesis 2: POS will be negatively related to job-induced tension.

\section{Leader-Member Exchange}

Leader-member exchange (LMX) theory is another theory that attempts to understand the role of reciprocity in the relationship between the employee and the employer and is another construct under examination in this study. This construct is particularly important in this context as a driver has limited interaction within the organization thus the focus on LMX and dyadic relations is well-suited to this study.

LMX is an approach to leadership that emphasizes that different types of relationships evolve between superiors and subordinates within their work units (Erdogan \& Bauer, 2010; Graen \& Uhl-Bien, 1995). LMX is a process by which supervisors and subordinates enter into and maintain social-exchange relationships. LMX relationships develop as a process of role-making between dyadic supervisor-subordinate pairs (Bauer \& Green, 1996; Dienesch \& Liden, 1986). As the role-making process unfolds, dyadic partners test each other through a series of progressively escalating trust-based exchanges.

The LMX relationship develops in stages: role-taking, role-making, and role routinization (Bauer \& Green, 1996; Graen \& Scandura, 1987; Dienesch \& Liden, 1986; Liden, Sparrowe, \& Wayne, 1997). In the first step of the LMX relationship development (role-taking), the relationship begins with the initial interactions between the members of 


\section{DRIVER TURNOVER AND JOB-INDUCED TENSION}

the dyad (supervisors and their subordinates). During these initial interactions, supervisors and their subordinates test one another through a sequence of exchanges and determine whether they can build the relational components of trust, respect, and obligation necessary for further, higher quality exchanges (Dienesch \& Liden, 1986). In the second step (role-making), supervisors and their selected subordinates continue to develop their relationships through further exchanges. In this process, the exchanges become more social and less economic (Bauer \& Green, 1996; Graen \& Uhl-Bien, 1995). Finally, in the last step (role-routinization), the exchange is maintained over time through collaborating on different tasks with trust, respect, loyalty, liking, support, and quality. However, leaders have limited resources and time for exchange, so they develop and maintain a high quality of exchange with a limited number of subordinates (Dienesch \& Liden, 1986; Graen, 1976). Therefore, the quality of LMX relationships varies from those that go beyond the formal employment contract (i.e., high quality LMX) to those based strictly on formal employment contracts (i.e., low quality LMX) (Bauer \& Green, 1996;

Dienesch \& Liden, 1986; Dulebohn et al., 2012; Gerstner \& Day, 1997; Graen \& UhlBien, 1995; Liden \& Maslyn, 1998; Liden et al., 1997).

As leaders treat individual subordinates differently, two different groups of subordinates emerge: those in the in-group and those in the out-group. The in-group consists of a small number of subordinates who are trusted and favored by the leader after a series of testing exchanges. The quality of the exchange relationship is high in that leaders and the in-group work beyond the formal work contract (Liden, Wayne, \& 


\section{DRIVER TURNOVER AND JOB-INDUCED TENSION}

Stilwell, 1993). The in-group, naturally, has the advantage of favorable support and resources from the relationship. They perform unstructured tasks with a high degree of autonomy and have additional responsibilities, often outside the scope of their job descriptions. Thus, the in-group may receive many benefits like organizational and jobrelated information, influence in decision-making, attention, greater job direction, and social networks (Dienesch \& Liden, 1986; Gerstner \& Day, 1997; Graen \& Uhl-Bien, 1995; Kamdar \& Van Dyne, 2007; Liden \& Maslyn, 1998; Liden et al., 1997).

Unlike the in-group, the out-group includes those to whom the leader is apathetic. Any relationship with the leader remains formal, with role-defined interactions. Exchanges between the leader and subordinates rely on the prescribed employment contract with more limited reciprocal trust and support. Thus, economic exchanges between leader and out-group are more salient than social exchanges. Also, the out-group receives fewer valued resources; the leader makes little attempt to motivate or develop the out-group. Subsequently, in these low quality relationships, subordinates may be at a relative disadvantage for job benefits and career progress (Vecchio, 1997). Compared to the in-group, the out-group have less access to the leader, receive fewer resources, and perform the more mundane tasks of the work unit with more restricted information and fewer rewards (Liden \& Graen, 1980). Therefore, out-group or low quality LMX is characterized by predominantly economic exchanges with low levels of mutual trust, interaction, liking, support, and influence (Maslyn \& Uhl-Bien, 2001).

LMX and turnover. LMX has been the focus of much research involving its 


\section{DRIVER TURNOVER AND JOB-INDUCED TENSION}

relationship to job performance (Bauer, Erdogan, Liden, \& Wayne, 2006; Liden, Erdogan, Wayne, \& Sparrowe, 2006), citizenship behaviors (Ilies, Nahrgang, \& Morgeson, 2007), job satisfaction and organizational commitment (Cohen-Charash \& Spector, 2001; Gerstner \& Day, 1997; Liden et al., 1997), but it is much more rare for it to have been included in a study of turnover (see Bauer et al., 2006 for a notable exception).

Harris, Kacmar, and Witt (2005) have suggested that low LMX may increase turnover intentions due to its negative impact on employees ${ }^{6}$ feelings and cognitions. Research has supported this notion with a number of studies examining LMX and turnover intentions (e.g., Harris, Harris, \& Brouer, 2009; Harris, Wheeler, \& Kacmar, 2009; Rockstuhl, Dulebohn, Ang, Soon, \& Shore, 2011). Less research has been conducted on LMX and actual turnover yet there is support that quality of LMX is related to turnover. For example, Nishii and Meyer (2009) in an examination of LMX mean and differentiation as potential moderators found support for the buffering quality of LMX on the diversity to turnover relationship. Bauer et al. (2006) found a negative relationship between LMX and turnover in a sample of new executives who were less extroverted. In a recent study, Sherman, Kennedy, Woodard, and McComb (2012) found that turnover varied across dyad perceptions of LMX. That is, turnover was the highest when there was a high level of differentiation between the member's and a leader's LMX score suggesting that the two parties perceive vastly different relationships. Furthermore, it has been argued that much leader-member exchange research lacks contextual emphasis (Cogliser \& Schriesheim, 2000; Dienesch \& Liden, 1986). A construct that by its very 


\section{DRIVER TURNOVER AND JOB-INDUCED TENSION}

nature that can provide organizational context to an examination of relationships between leaders and followers is job embeddedness (Mitchell et al., 2001). As such, recent studies have examined the role of embeddedness in the LMX framework For example, LMX has been found to increase the formation of embeddedness which in turn predicts turnover (Harris et al., 2011) and can also acts as a moderator in the effectiveness of HR management and job embeddedness relationship (Wheeler, Harris, \& Harvey, 2010) Finally, meta-analytic findings, albeit based on a very small number of samples, indicate that the quality of leader member exchange is negatively related to intended turnover (Gerstner \& Day, 1997) and actual turnover (Dulebohn et al., 2012). Accordingly, firms have sought to maximize LMX perceptions among subordinates as a strategy for reducing turnover.

Due to the context within the trucking industry, truck drivers and their supervisors are constrained in their opportunities to develop favorable supervisory-subordinate exchanges. Hence, the potential for drivers to experience poor LMX is increased and truck drivers may therefore give greater consideration to quitting than is typical in other work settings. In a study on truck drivers, Morrow et al. (2005) found that LMX had a curvilinear relationship with turnover. This study will attempt to refute this finding and replicate previous work reviewed above by proposing a linear relationship.

Hypothesis 3: LMX will be negatively related to turnover.

LMX and job-induced tension. Little research has examined the relationship between LMX and job-induced tension (Brouer \& Harris, 2007) but it could be argued 


\section{DRIVER TURNOVER AND JOB-INDUCED TENSION}

that LMX quality is equally related to work tension. That is, those subordinates with high-quality LMX relationships often become the employees that leaders go to when they need something important done (Liden \& Graen, 1980). Such subordinates therefore experience fewer adverse workforce pressures, such as role ambiguity, job uncertainty, role overload, or role insufficiency; they are more likely to view their superiors' treatment as fair; and they are less likely to file grievances than their out-group counterparts (Gerstner \& Day, 1997; Lagace, Castleberry, \& Ridnour, 1993; Peiró, Gonzalez-Roma, Ramos, \& Zornoza, 1996; Nelson, Basu, \& Purdie, 1998; Scandura, 1999; Tanner, Dunn, \& Chonko, 1993; Tordera, González-Romá, \& Peiró, 2008). This logic stems from the notion that subordinates in high-quality LMX relationships are able to maintain lower levels of tension because many of the role stressors that lead to work tension (e.g., uncertainty, ambiguity) are ameliorated through higher levels of information, trust, and emotional support coming from their supervisors. In support of this idea, the few results from the existing research on the LMX/work-tension relationship have found a negative relationship between LMX quality and various indicators of work tension. In a study of call center workers Huang, Chan, Lam and Nan (2010) found that LMX was negatively related to burnout. As mentioned above Thomas and Lankau (2009) found quality of LMX related negatively to emotional exhaustion. Finally, there are two interesting studies examining the LMX and job-induced tension relationship. Hochwarter and Byrne (2005) found a curvilinear relationship between LMX and job-induced tension in a sample of police officers while Brouer and Harris (2007) found that high LMX was 


\section{DRIVER TURNOVER AND JOB-INDUCED TENSION}

positively related to job-induced tension for those high in negative affectivity. Due to the conflicting and sparse state of the current literature this study has the potential to illuminate the relationship between LMX and job-induced tension.

Utilizing a COR theory framework, and the general review of the LMX literature suggesting that employees reporting high levels of LMX are treated more favorably, given more consideration and attention, and included in more work-related activity by their supervisor than those reporting low levels of LMX higher LMX quality can be seen as a source of resources that has the potential to mitigates the impact work stress. That is, social support, favorable treatment, and higher levels of organizational information that is a result of LMX is a particularly important mechanism through which workers can replenish their resources. Therefore, I propose the following.

Hypothesis 4: LMX will be negatively related to job-induced tension.

The above section serves to provide the reasoning behind the hypothesized main effects. See Figure 2 for a graphical representation of these hypothesized relationships. Next I discuss the role of dispatcher communication effectiveness as key components in this study's model.

\section{Dispatcher Voice and Responsiveness}

A means by which employees help their organizations to innovate and successfully adapt to dynamic business environments is through "voice" - the expression of constructive opinions, concerns, or ideas about work-related issues (Van Dyne, Ang, \& Botero, 2003). For example, employees' voice about improvements to or existing failures 


\section{DRIVER TURNOVER AND JOB-INDUCED TENSION}

in the work process has been associated with positive organizational outcomes such as team learning (Edmondson, 1999) and improved work processes and innovation (Argyris \& Schon, 1978). While Van Dyne and colleagues (2003) broadened the definition of voice to include the expression of both constructive suggestions and concerns, much of the recent research on voice has focused more heavily on "promotive" aspects of voice, or expressions of ways to improve existing work practices and procedures to benefit organizations (e.g., Van Dyne \& LePine, 1998). In comparison, less empirical attention has been paid to "prohibitive" aspects of voice, or expressions of individuals' concern about existing or impending practices, incidents, or behaviors that may harm their organization, despite early definitions of voice that focused on it as a means of stopping or changing objectionable states of affairs (Rusbult, Farrell, Rogers, \& Mainous, 1988; Withey \& Cooper, 1989). So although the common examination of voice behavior in the organizational literature examines voice as a proactive behavior it can also be examined as voice of concern. One such theory that considers voice as an expression of concern or discontent is Hirschman's theory of exit, voice, and loyalty.

In his influential work on individual response to decline in firms, organizations, and states, Hirschman (1970) proposed that individuals affected by decline primarily resort to one of either of the two courses of action: exit and voice. By exit Hirschman assumed the act of leaving the organization and by voice - "any attempt at all to change, rather than to escape from, an objectionable state of affairs" (Hirschman, 1970, p. 30). As such, this study refers to "voice" as the use of direct communications to bring actual and 


\section{DRIVER TURNOVER AND JOB-INDUCED TENSION}

desired conditions closer together.

Voice reduces the probability that workers will quit by providing workers with a voice and management with a response in determining rules and conditions of work. This can lead to a more stable workforce than where voice alternatives to exit do not exist or are not used. In Hirschman's (1970) framework, employee dissatisfaction with product or process can result in exit (e.g., employees switching jobs) or voice, whereby the dissatisfied stick with the organization and try to make their specific qualms or recommendations known to those with the power to act. Voice requires organizational members to endure the deterioration for a period of time. Voice is costly in terms of effort and time, it requires patience and willingness to put up with uncertainty. By using voice, organizational members can elaborate on the nature and intensity of their discontent and suggest, ask, or demand specific corrective actions.

Hirschman argued that exit undermines voice primarily through depriving the dissatisfied consumers or members of organizations of their most articulate and influential carriers of voice. Hirschman did not elaborate on how soon after the point of dissatisfaction members begin exercising exit or voice and whether the choice between exit and voice remains salient for a particular period of time. Arguably, as significant time elapses after point of dissatisfaction and no improvement in the state of affairs is observed, the choice between exit and voice becomes less salient. Those members who did not exit after the point of deterioration and who perceive no improvement in their conditions may realize that they had made a mistake by staying and still exit. Hence, new 


\section{DRIVER TURNOVER AND JOB-INDUCED TENSION}

exits can continue to occur for some time after the point of deterioration. Conversely, new voice may require a new point of deterioration or another change for the worse in order to emerge. For example, in the language of Lee and Mitchell (1994) new voice may occur due to the presence of a shock. Then, responding to yet another change for the worse, the choice between exit and voice would become salient again and persons affected by the change would engage in individual calculations regarding whether to exit or exercise their voice.

According to Hirschman, the exit-voice calculations are based on the essentially rational decision-making process whereby persons weigh possible payoffs against likely costs before choosing to proceed with a particular course of action. Generally, people choose a course of action when the cost-benefit ratio associated with it compares favorably with the cost-benefit ratio of the best alternative course of action. That is, people would choose exit when the net improvement they would derive from exiting after subtracting the costs of exit would be greater than the net improvement they would derive from exercising voice after subtracting the costs of voice. In the event that little or no net improvement was associated with either exit or voice, individuals would likely refrain from expressing grievances altogether and wait for someone or something else to improve matters. In this sense, those that are more embedded (Mitchell et al., 2001) within their jobs or community may be more likely to choose voice opposed to exit.

The idea of possible improvement in the state of affairs is essential to Hirschman's theory. When choosing to respond to decline by exercising either voice or 


\section{DRIVER TURNOVER AND JOB-INDUCED TENSION}

exit, those affected by the decline believe that their situation can be improved. If they choose to exit, they believe that by leaving they will improve their situation and that things will be better for them elsewhere. If they choose to stay where they are and voice their dissatisfaction, they believe that by speaking out and participating they will change the objectionable state of affairs and improve their current matters. Hence, exit and voice can be thought of as alternative individual responses to situations that are believed to be improvable. Otherwise, if individuals do not believe in the possibility of improvement in their situation, the choice between exit and voice loses its consequence.

Hirschman's framework has been applied in differing contexts and has been used to examine a variety of relationships including in the context voting behavior (Weber, 2011), and most prominently, workplace related contexts (e.g., Farrell, 1983; Hoffman, 2006; Turnley \& Feldman, 1999; Withey \& Cooper, 1989). In the truck-driving context this translates into a driver's voice behavior and the responsiveness of the organization. Dispatchers have the unique role as being the primary contact for the driver to the organization (Ozment \& Keller, 1999). The research on driver retention finds that driver attitudes toward dispatchers can play an important part in driver satisfaction (Richard et al., 1995) and turnover intentions (Richard, LeMay, Taylor, \& Turner, 1994). To encourage more helpful treatment of drivers, retention, and performance, Taylor (1991) suggests evaluating dispatchers on driver performance and turnover. Others have derived similar conclusions that performance is enhanced as dispatchers create healthier relationships with drivers (Keller \& Ozment 1999b; LeMay, Taylor, \& Turner 1993; 


\section{DRIVER TURNOVER AND JOB-INDUCED TENSION}

Stephenson \& Fox 1996; Taylor \& Cosenza 1998). For example, in a study of 1,500 lessthan-truckload (LTL) carriers Richard et al. (1995) found that driver turnover was related to the drivers' assessment of dispatchers' friendliness and approachability, competence, fairness, and interest in the drivers' welfare. The dispatcher is the linking pin between the driver and the organization. As such, the dispatcher is in the position as the recipient of a driver's voiced discontent and plays a very important role in driver satisfaction and decision to turnover.

It is the premise of this study that in situations where POS and LMX are low a driver will be more likely to exit or voice. Whereas, some drivers will exit it stands that some will also voice discontent. In line with Hirschman (1970), I predict drivers that utilize voice expect that there is the possibility of improvement. Thus, to the extent the dispatcher remains sensitive to the drivers' concern then dispatcher sensitivity to voice would act as a potential buffer in the negative relationships between POS, LMX, and the outcomes of turnover and job-induced behavior.

Hypothesis $5 a$ \& $6 a$ : Dispatcher sensitivity to voice will moderate the relationship between POS, turnover (5a), and job-induced tension (6a). Specifically, there will be a weaker negative relationship when dispatcher sensitivity to voice is high rather than low.

Hypothesis $7 a \& 8 a$ : Dispatcher sensitivity to voice will moderate the relationship between LMX, turnover (7a), and job-induced tension (8a). Specifically, there will be a weaker negative relationship when dispatcher sensitivity to voice is high 


\section{DRIVER TURNOVER AND JOB-INDUCED TENSION}

rather than low.

As noted by Keller and Ozment (1999b) sensitivity, in this sense, refers to an attitude, and works as an antecedent to a responsive behavior. Therefore, dispatchers who place importance on listening to driver concerns are likely to respond in a proactive manner to help resolve driver problems before they escalate to the point where drivers are willing to quit. Responsiveness, depicted as a behavior, is identified as the degree of action taken by a dispatcher to resolve driver issues (Keller \& Ozment, 1999b). For example, a responsive dispatcher will help resolve a driver complaint concerning equipment. Regardless of the urgency, the fact that the dispatcher provided thorough and expeditious feedback helps to retain that driver (Ozment \& Keller, 1999). As such, I expect that dispatcher sensitivity to voice will be positively related to dispatcher responsiveness. That is, a dispatcher must be sensitive to driver voice in order to be responsive to a driver's concerns.

According to Hirschman (1970) when one chooses to voice their dissatisfaction, they believe that by speaking out and participating they can improve their current state of affairs. That is, when one voices discontent they expect change. What then is the outcome if no change occurs? In a study of union versus non-union (i.e., direct) voice, Bryson, Charlwood, and Forth (2006) found that manager responsiveness predicted performance after controlling for voice type and amount indicating that responsiveness was more critical in determining organizational outcomes. Keller and Ozment (1999a) tested a model in dispatcher responsiveness mediated the relationship between driver sensitivity 


\section{DRIVER TURNOVER AND JOB-INDUCED TENSION}

to voice and driver turnover. They found that dispatcher responsiveness, the degree of action taken by a dispatcher to follow through and resolve driver issues, is important for reducing driver turnover. Building on this limited, but telling, research I propose that dispatcher responsiveness will decrease the negative relationship between the two independent variables, POS and LMX, and the two outcome variables of turnover and job-induced tension.

Hypothesis $5 b-8 b$ : Dispatcher sensitivity to voice will be positively associated with dispatcher responsiveness.

Hypothesis 5c \& 6c: Dispatcher responsiveness weakens the association between POS, turnover, and job-induced tension.

Hypothesis 7c \& $8 c$ : Dispatcher responsiveness weakens the association between LMX, turnover, and job-induced tension.

The above hypotheses predict that responsiveness partially mediates the moderating effect of sensitivity of voice on the relationships between the independent and the outcome variables. Formally stated, this study proposes that the moderating effects of dispatcher sensitivity to voice on the main effect relationships between POS, LMX, and the outcomes of turnover and job-induced tension will be partially mediated by dispatcher responsiveness.

Hypothesis $5 d \& 6 d$ : Dispatcher responsiveness partially mediates the moderating effect of dispatcher sensitivity to voice on the relationship between POS, turnover, and job-induced tension. 


\section{DRIVER TURNOVER AND JOB-INDUCED TENSION}

Hypothesis $7 d \& 8 d$ : Dispatcher responsiveness partially mediates the moderating effect of dispatcher sensitivity to voice on the relationship between LMX, turnover, and job-induced tension.

Putting this all together, I expect that when 1) sensitivity to voice moderates the relationship between POS (or LMX) and turnover (or job-induced tension) as in Hypotheses $5 a-8 a$; that 2 ) the moderating variable, sensitivity to voice, causes the mediating variable, responsiveness, as in Hypotheses $5 b-8 b$; and 3) the mediating variable, responsiveness, moderates the relationships between the independent variables and the outcome variables, as in Hypotheses $5 c-8 c$; and then this will 4) partially eliminate the moderating effects of the original moderator, sensitivity to voice. See Figures 2 - 5 for a visual representation of the proposed hypotheses. 


\section{DRIVER TURNOVER AND JOB-INDUCED TENSION}

\section{Chapter 2 \\ Method}

\section{Procedure and Sample}

This study was aided by a number of on-site visits that took place during the course of the study. In fact, the relational focus of this study was in part due to these site visits and my observations of the interactions that took place between a driver, their peers, their supervisor, and their dispatcher. I was also invited to attend a 2-day driver training in order to get a more holistic understanding of what it means to be a truck driver. These site visits and the participation in the driver training deepened my understanding of the phenomena under investigation and helped my contextual knowledge of the trucking industry.

This study utilizes a time-lagged design (Pitariu \& Ployhart, 2010; Ployhart \& Vandenberg, 2010) for all hypotheses relating to turnover (Hypotheses 1, 3, 5, 7) as all company employees were asked to complete surveys at Time 1. Demographics were also collected from company records at that time and then, subsequently, turnover data were gathered from company records at Time 2 (6 months after respondents completed surveys). For the hypotheses relating to job induced tension (Hypotheses 2, 4, 6, 8), a cross-sectional design was employed for three specific reasons. First, given that physiological biomarker data collection was not possible for this study; self-reported tension was felt to be the next best thing as the employees themselves are in the best position to report feelings of stress (Lazarus \& Folkman, 1984). Second, the organization was not able to support multiple data collections so we opted for full organizational 


\section{DRIVER TURNOVER AND JOB-INDUCED TENSION}

support for a single data collection. And finally, third, the use of turnover from company records allowed me to employ a time-lagged design for half of the hypotheses which served to partially allay threat to validity concerns compared to a fully cross-sectional design.

All data for the current study were collected from a privately held trucking company in the Pacific Northwest. The company provides logistic and transportation services to its customer base. The company facilitates the movement of more than 300,000 truckloads each year and provides services to over 5,000 customers across the U.S. and Canada. The company employs approximately 600 people. Relevant job titles include company driver, owner-operator, and fleet manager. Of these, all company and owner-operator drivers were invited to participate. While participation rates are relatively low in a driving population, a number of techniques were used to increase participation. First, a letter of support from the Vice President of Operations from the participating organization was included with each survey. Second, all participants were entered into a lottery and had the chance to win either one $\$ 500$ gift card or one of four $\$ 50$ gift cards. Third, due to the unique sample of truck drivers and the fact that many drivers rarely interact with the organization and are home sporadically, the participating company thought that the novelty of a $\$ 2$ bill sent along with each initial survey would garner more attention. Thus, this incentive was included along with each survey as an incentive. Finally, given the found effectiveness of sending reminders to potential survey participants (Dillman, 2011), about a month after sending an initial survey, a reminder 


\section{DRIVER TURNOVER AND JOB-INDUCED TENSION}

and another survey was sent to all of the potential participants that did not respond.

Of the 359 potential driver participants, 166 of these drivers returned completed surveys yielding a response rate of $46 \%$. One-hundred sixty-one of these participants were male $(96.9 \%)$ and 5 were female. Women compose approximately $5 \%$ of the total over-the-road (OTR) drivers (Department of Labor, 2010) thus this number of women participants is lower but consistent with the field. Participants reported, on average, 18.82 years of professional driving $(S D=10.92), 6.81$ years of tenure $(S D=6.56)$ at their current organization, an average of 2.89 days away from home per dispatch $(S D=3.01)$ and about 51.70 driving hours per week $(S D=13.20)$. The average participants age was 54 years $(S D=9.47)$ and most participates were white $(34.5 \%)$.

Independent t-tests were conducted to assess if non-respondents differed from respondents on the demographics gathered from company records. There were no mean differences in the tenure between respondents $(M=6.81, S D=6.56)$ and non-respondents $(M=5.90, S D=5.52), t(357)=-1.42, p=.16$. However, there were significant mean differences in the age of respondents and non-respondents $(M=51.23, S D=9.65) t(357)$ $=-3.02, p<.05$ with non-respondents being younger. A chi-square test of independence was conducted to examine the relationship between respondent, non-respondent, and turnover. This relationship was not significant, $X^{2}(2, N=359)=1.176, p=.278$ thus turnover did not significantly differ between those who responded to the survey and those who did not.

\section{Measures}




\section{DRIVER TURNOVER AND JOB-INDUCED TENSION}

Perceived organizational support. POS was measured using 8-items developed by Eisenberger, Huntington, Hutchison, and Sowa (1986). A sample item is "My organization appreciates any extra effort from me." Cronbach's alpha with this sample was .96.

Leader-member exchange. LMX was measured using 7 items adapted from Scandura and Graen (1984). The items were modified based on the wording used by Liden, Wayne, and Stilwell (1993). An example item is "I can count on my supervisor to "bail me out" even at his/her own expense, when I really need it." Cronbach's alpha with this sample was .94 .

Job tension. Job tension was measured using House and Rizzo's 7-item measure of job tension (1972). A sample item is "Problems associated with my job have kept me awake at night." Cronbach's alpha with this sample was .90

Dispatcher communication effectiveness. Ozment and Keller (1999) argue that sensitivity to voice is the attitudinal antecedent of dispatcher responsiveness. In their exploration of these two constructs they conducted a confirmatory factor analysis (CFA) and found these two constructs to have discriminant validity. Thus, it is on this assumption that I proposed my hypotheses. I intended to measure dispatcher sensitivity to voice with 4-items from Keller and Ozment (1999a) and dispatcher responsiveness with 5 items from Keller (2002). Yet upon examination of the sensitivity to voice measure (e.g., my dispatcher acts like it is important to get feedback from drivers) the items appeared to 


\section{DRIVER TURNOVER AND JOB-INDUCED TENSION}

be behavioral (e.g., the inclusion of the words act and encourage) and would not act as an antecedent to dispatcher responsiveness but instead these two variables may be one factor.

Thus, questions were raised about the distinctiveness of dispatcher sensitivity to voice and dispatcher responsiveness. As such, a Principal Axis Factor (PAF) with a Varimax (orthogonal) rotation was conducted. The PAF revealed that 4 of the items in the measures either did not load on their respective latent variables or showed high crossloadings. A confirmatory factor analysis was conducted to further examine the two dispatcher variables. Using AMOS (Arbuckle, 1999), I examined the 2-factor model with the problematic items removed (i.e., item 3 on the sensitivity scale and items 2, 4, and 5 of the responsiveness scale). This 2-factor model with items removed demonstrated adequate fit statistics $\left(\chi^{2}=6.07, \mathrm{df}=4 ; \mathrm{GFI}=.99 ; \mathrm{CFI}=.99 ; \mathrm{RMSEA}=.06\right)$. But there were remaining concerns. First, the two dispatcher variables showed high co-variance at .85 indicating that there may be issues with discriminate validity. Second, these two variables showed high multicollinearlity with the other independent variables in the model. Thus, given the results of the PAF, CFA, a close examination of the face validity of the items, and the potential problems with multicollinearlity it was determined the new composite variable would be the best way to test my main hypotheses.

This new composite variable was named Dispatcher Communication Effectiveness as this was the name given to the dispatcher variables from Ozment and Keller (1999). Dispatcher Communication Effectiveness has 5 items (see Appendix A for a comparison of items in each measure). An example item for this measure is "My 


\section{DRIVER TURNOVER AND JOB-INDUCED TENSION}

dispatcher acts like it is important to get feedback from drivers". Cronbach's alpha with this sample was .91.

Participants indicated the extent to which they agree or disagree with items on a 7-point scale ranging from 1 (strongly disagree) to 7 (strongly agree) on all of the above measures (see Appendix B for all items).

Turnover. Turnover was assessed via organization records 6 months after surveys were administered. Respondents were coded as 1 for stayers and 0 for leavers. The company records revealed that 78 drivers left the organization. Of these, 34 of the "leavers" had completed surveys.

Abelson (1987) categorized turnover into whether the turnover was voluntary or involuntary from the employee's perspective and avoidable or unavoidable from the organization's perspective. Therefore, there are two turnover categories of interest, employees who stay with the organization and employees who leave for voluntary, organizationally avoidable reasons. The latter category refers to turnover that reflects the individual's choice to leave and turnover the organization may have been able to avoid (e.g., through time home increases, pay raises, etc.). Organizationally unavoidable turnover is not of primary interest because these employees did not withdraw because of dissatisfaction with the job. Abelson (1987) found that employees who leave the organization for unavoidable reasons are more similar attitudinally to people who stay than to those who leave for organizationally avoidable reasons. Therefore, the exploration of turnover models should occur with organizationally avoidable turnover (Hom \& 


\section{DRIVER TURNOVER AND JOB-INDUCED TENSION}

Griffeth, 1995). Furthermore, a number of studies examining driver turnover indicate that voluntary turnover is of primary concern in the driving industry (e.g., de Croon et al., 2004; Keller, 2000; Morrow et al., 2005) therefore, 6 drivers that left the organization involuntarily were excluded from the analyses.

Control variables. A number of potential control variables were included to minimize or eliminate potential spurious relationships in the study. Previous research has indicated that overall health has been shown to be related to job-induced tension (Jamal, 1990) and turnover (Hedberg \& Langendoen, 1989) and as such this was used as a control variable. The influence of tenure on turnover makes it a potential control variable as the amount of tenure with an organization often increases the personal costs of leaving a job (Mitchell et al., 2001). Number of previous employers was controlled because research suggests that past quits are predictive of future quits (i.e., the hobo syndrome) (Ghiselli, 1974; Judge \& Watanabe, 1995). Time home, hours on the road each week, and miles per dispatch were also controlled for based on previous research indicating their relationship with turnover (e.g., Suzuki et al., 2009) and work stress (e.g Shattell, Apostolopoulos, Sönmez, \& Griffin, 2010).

An examination of the correlation matrix indicated that all other demographic information (e.g., ethnicity, relationship status, age, education level, children in home, years driving) was not strongly correlated to the outcome variables (i.e., none were over .13) and thus were not included as control variables. Finally, while the number of dispatchers and sample size will not allow a test for the effects of potential nesting of 


\section{DRIVER TURNOVER AND JOB-INDUCED TENSION}

driver in dispatcher in a multilevel model I tested the effects of dispatcher on the outcome variables using one-way analyses of variance (ANOVA) and a chi-square test of independence. These tests were non-significant indicating that there were no differences in the outcome variables due to the effects of dispatcher. Furthermore, upon examination of the correlation matrix the variable, dispatcher, was not highly correlated with any of the other study variables thus dispatcher was not included as a control variable. Finally, it was not necessary to control for gender as the majority of the sample was male $(96.9 \%)$. Following the theoretical and statistical conclusions stated above when tension was the dependent variable the following control variables were added to the analyses: overall health, miles per dispatch, weekly drive hours, and days away per dispatch. The following control variables were used when turnover was the dependent variable: overall health, miles per dispatch, weekly drive hours, days away per dispatch, tenure, and number of previous employers. 


\section{DRIVER TURNOVER AND JOB-INDUCED TENSION}

\section{Chapter 3 \\ Results}

\section{Preliminary Data Analysis}

The data was examined according to Tabachnick and Fidell (2007) to determine whether the regression assumptions of normality, linearity, and homoscedasticity of residuals hold. The absence of outliers was determined by examining the standardized residuals of each variable and none were less than -3.3 and more than 3.3 (Tabachnick \& Fidell, 2007) and by examining the residual plots. These preliminary analyses confirmed compliance with the assumptions of multiple regression.

Confirmatory Factor Analyses. Table 1 shows means, standard deviations, intercorrelations, and reliabilities of study variables. LMX and POS were highly correlated at $r=.64, p<.01$ in this sample. POS and LMX are both based on SET and have conceptual similarities. Given the concern that these two constructs are not distinct from one another I compared the 2-factor model to a 1-factor model (i.e., LMX and POS on one latent variable) using confirmatory factor analysis (CFA) in AMOS (Arbuckle, 1999). The 2-factor model demonstrated better fit $\left(\chi^{2}=222.70, \mathrm{df}=89\right.$; GFI $=.84$; CFI $=.94 ; \mathrm{RMSEA}=.09)$ compared to the 1 -factor model $\left(\chi^{2}=226.87 \mathrm{df}=90 ; \mathrm{GFI}=.82\right.$; $\mathrm{CFI}=.93 ; \mathrm{RMSEA}=.10)$ thus justifying treating these as two different constructs. This is consistent with previous studies that have determined that these two constructs have unique antecedents and are differentially related to outcome variables (e.g., Erdogan, Kraimer, \& Liden, 2004; Wayne et al., 1997). 


\section{DRIVER TURNOVER AND JOB-INDUCED TENSION}

Dispatcher communication effectiveness was highly correlated with POS $(r=.61$, $p<.01)$ and $\operatorname{LMX}(r=.68, p<.01)$, and thus I conducted a confirmatory analyses with these variables to ascertain their discriminant validity. The two-factor model for

dispatcher communication effectiveness and POS had better fit $\left(\chi^{2}=176.10, \mathrm{df}=64\right.$; GFI $=.87 ; \mathrm{CFI}=.94 ; \mathrm{RMSEA}=.10)$ than the one factor model $\left(\chi^{2}=180.43, \mathrm{df}=65 ; \mathrm{GFI}\right.$ $=.86 ; \mathrm{CFI}=.95 ; \mathrm{RMSEA}=.11)$ indicating that dispatcher communication effectiveness and POS were two distinct variables. Furthermore, the two factor model for dispatcher communication effectiveness and LMX had better fit $\left(\chi^{2}=97.5\right.$, $\mathrm{df}=53$; GFI $=.91$; CFI $=.97 ; \mathrm{RMSEA}=.07)$ than the one factor model $\left(\chi^{2}=108.74, \mathrm{df}=54 ; \mathrm{GFI}=.90 ; \mathrm{CFI}\right.$ $=.95 ; \mathrm{RMSEA}=.08)$. These analyses indicate that dispatcher communication effectiveness, POS, and LMX are distinct variables and provide justification for analyzing these as such.

\section{Hypotheses Analysis Strategy}

The current study aimed to examine the relationships between POS and LMX on job-induced tension and turnover. These relationships were originally proposed to be moderated by dispatcher sensitive to voice and then, in turn, this moderation was to be mediated by dispatcher responsiveness. Due to measurement issues (i.e., discriminant validity, multicollinearlity) associated with the original variables, dispatcher sensitivity to voice and dispatcher responsiveness, a number of the hypotheses dropped out of the model and modified hypotheses were added to the study. The testing of the hypotheses were conducted to investigate this parallel but modified model in which the new 


\section{DRIVER TURNOVER AND JOB-INDUCED TENSION}

composite variable, dispatcher communication effectiveness, acts as a moderator in the main effect relationships. Table 2 and Figures 7 and 8 display a summary of the changes.

Hypotheses 1- 4 examined the main effects of LMX and POS on the outcome variables of turnover and job-induced tension while Hypotheses 5e-8e (i.e., the modified hypotheses) examined the moderating effects of dispatcher communication effectiveness on these relationships. Control variables were entered in Step 1 of the regression analysis, followed by POS or LMX in Step 2. In those hypotheses examining moderations, the centered variables of POS, LMX, and dispatcher communication effectiveness were entered in Step 3 followed by the interaction term in the final step of the regression model. Regression analyses were also run without control variables to investigate any potential differences in the findings. No meaningful differences were found with regard to relationships between study variables or significance levels.

\section{Hypotheses Testing}

The bivariate results indicate that while POS and LMX were significantly correlated with job-induced tension ( $r=-.40, r=-.25$, respectively) in the expected direction only weak relationships were found between these predictors and turnover $(r$ $=.12, r=.07$, respectively). To further investigate these relationships a series of logistic and hierarchal linear regression analyses were conducted. Tables 3-8 provide results of these analyses.

Logistic regression analysis. Hypotheses 1 and 3 proposed negative relationships between the independent variables POS and LMX and the outcome variable turnover. 


\section{DRIVER TURNOVER AND JOB-INDUCED TENSION}

Because the dependent variable, turnover, was a categorical variable with two possible outcomes, binary logistic regression analysis was used to test these relationships. In order to take into account any spurious effects (Tabachnick \& Fidell, 2007) and to ensure that I was capturing the effects of POS and LMX above and beyond previous established relationships I entered the control variables; overall health, miles per dispatch, weekly drive hours, days away per dispatch, tenure, and number of previous employers in the first step of the logistic regression procedure. These control variables were selected based on their theoretical relevance and their relationships with the outcome variables as indicated in the correlation matrix. In Step 2 the two predictor variables, POS and LMX were entered. The results of the logistic regression analysis are summarized in Table 3. The full model (Step 2) failed to show the presence of nonadditive effects of POS and LMX on the prediction of turnover after controlling for differences in overall health, miles per dispatch, weekly drive hours, days away per dispatch, tenure, and number of previous employers, indicating no support for Hypotheses 1 and 3. In particular, there was no support for the main effects of POS on turnover $(B=.28, S E=.18, \log$ odds $=$ $1.33, p=.13)$. Furthermore a main effect relationship between LMX on turnover was not supported $(B=.16, S E=.18, \log$ odds $=1.17, p=.34)$.

Hypotheses 5e and 7e proposed that dispatcher communication effectiveness would moderate the relationships between POS, LMX, and turnover. In particular, these modified hypotheses, based on the original theorizing of the study, predicted that there 


\section{DRIVER TURNOVER AND JOB-INDUCED TENSION}

would be a weaker negative relationship between POS, LMX, and turnover when dispatcher communication effectiveness is high rather than low.

POS, LMX, and dispatcher communication effectiveness were centered before being entered in Step 3 of the logistic regression procedure in order to avoid multicollinearlity (Tabachnick \& Fidell, 2007) and to aid in the interpretation of the results (Howell, 2010). The full model in step three failed to show significant results indicating no support for Hypotheses 5e and 7e. In particular there was no support for the interactive effects of POS and dispatcher communication effectiveness on turnover $(B=$ $.04, S E=.12, \log$ odds $=1.04, p=.73)$. Furthermore these was no support for the interactive effects of LMX and dispatcher communication effectiveness on turnover $(B=$ $-.11, S E=.10, \log$ odds $=.90, p=.30)$. The results of these analyses are presented in Table 4 and 5.

Hierarchal linear regression. Hypotheses 2 and 4 proposed negative relationships between the independent variables POS and LMX with the outcome variable job-induced tension. In Step 1 of the regression analysis the control variables, overall health, miles per dispatch, weekly drive hours, and days away per dispatch, were added to the model. In Step 2 the two primary predictor variables, POS and LMX were entered. The results of the regression analysis are summarized in Table 6. Results indicate support for Hypotheses 2 and 4. In particular, a significant relationship was found for main effect relationships between POS on job-induced tension $(\beta=-.47, t(124)=-6.27, p<.001)$ and LMX and job-induced tension $(\beta=-.25, t(124)=-2.96, p<.01)$. 


\section{DRIVER TURNOVER AND JOB-INDUCED TENSION}

Hypotheses 6e and 8e proposed that dispatcher communication effectiveness would moderate the relationships between POS, LMX, and job-induced tension. In particular, these modified hypotheses, based on the original theorizing of the study, predicted that there would be a weaker negative relationship between POS, LMX and job-induced tension when dispatcher communication effectiveness is high rather than low. POS, LMX, and dispatcher communication effectiveness were centered before being entered into the models in order to avoid multicollinearlity and aid in interpretation (Howell, 2010; Tabachnick \& Fidell, 2007) and were entered in Step 3 of the regression analyses.

The full model in Step 3 failed to show support for Hypothesis 6e (Table 7). The interaction term did not predict job-induced tension above and beyond the effects of the other variables. That is, there was no significant change in $\mathrm{R}^{2}(\beta=.03, F(1,122)=8.64$, $\left.p=.74, \Delta R^{2}=.00\right)$ indicating that dispatcher communication effectiveness did not have an interactive effect on the relationship between POS and job-induced tension.

Hypothesis 8e (Table 8) examined the moderating effect of dispatcher communication effectiveness on the relationship between LMX and job-induced tension. The full model in Step 3 shows marginally significant $(p<.10)$ results after controlling for overall health, miles per dispatch, weekly drive hours, days away per dispatch, tenure, and number of previous employers in the relationship between LMX, job-induced tension, and the interaction term dispatcher communication effectiveness $(\beta=.14$, $\left.F(1,118)=4.90, p=.09, \Delta R^{2}=.02\right)$. Figure 9 presents a graphical representation of this 


\section{DRIVER TURNOVER AND JOB-INDUCED TENSION}

interaction. Although it appears that job-induced tension is highest under conditions of low LMX and low dispatcher communication effectiveness this interaction should be interpreted with caution as simple slopes analysis indicted that the slopes did not differ

from 0 . In particular, a test of simple slopes suggested neither the slope of low dispatcher communication effectiveness $(t=-1.61, p=.11)$ nor the slope for high dispatcher communication effectiveness were significant $(t=.350, p=.73)$ (Aiken \& West, 1991). 


\section{DRIVER TURNOVER AND JOB-INDUCED TENSION}

\section{Chapter 4 \\ Discussion}

Voluntary turnover rates among truckload carriers are extremely high, ranging from $50 \%$ to more than $100 \%$ annually (Griffin \& Kalnbach, 2002). Apart from the obvious economic consequences, high turnover might upset the social-psychological equilibrium of the organization, resulting in impaired relationships and increased stress and instability (Allen, Weeks, \& Moffitt, 2005). Furthermore, long-haul truck drivers operate in a stressor-filled environment, which exerts enormous adverse influence not only their well-being but also on their intent to quit. It was the intent of this study to explore the relational aspects of the driver's work environment to highlight how the relationships that a driver has with their organization, supervisor, and dispatcher predict turnover and job-induced tension that is inherent in the trucking industry.

The results support the theoretical underpinnings of POS and LMX to indicate that the social exchange relationships that one has with their organization and/or supervisor can influence job-induced tension. Yet, this study builds on the propositions of SET to integrate COR theory enabling me to characterize POS and LMX as resources that a truck driver may utilize in the face of job demands. Furthermore, utilizing Hirschman's Loyalty, Exit, and Voice framework this study proposed that drivers, faced with high job demands, either exit the organization or voice their discontent. The dispatcher plays a very important role in interpreting this voice behavior and responding appropriately to driver concerns. There were a number a measurement issues with the dispatcher variables, dispatcher sensitivity to voice and dispatcher responsiveness, thus a 


\section{DRIVER TURNOVER AND JOB-INDUCED TENSION}

composite variable was created that allayed the measurement problems. This composite variable, dispatcher communication effectiveness, demonstrated model fit and high reliability. Thus I was able to maintain the core theoretical framework and the driving purpose of the study to examine the role of the dispatcher in this high turnover and stressor-filled work environment. This study's main contributions were to establish the importance of POS and LMX on job-induced tension in a truck-driving context and to highlight the important role of dispatchers. This is the first study to examine the potential buffering effects of dispatcher communication effectiveness and lends to the understanding of the dynamics between a driver and their dispatcher.

\section{Summary of Findings}

The general guiding principle in my hypotheses formation was that in environments of high stress the relationships formed within the organization play an important role in mitigating negative organizational consequences. In particular, utilizing Social Exchange and COR theories this study hypothesized that these relationships in the form of POS and LMX decrease turnover and the inherent job-induced tension faced by

drivers. Second, when a driver has weak social exchange relationships, the effectiveness of the dispatcher to communicate concern toward driver voice can help to buffer the negative relationship between POS and LMX on turnover and job-induced tension.

POS and LMX on turnover. Contrary to expectations POS and LMX were not significantly related to turnover. The POS literature indicates that POS's effects on the turnover process may be fully mediated through global, affect-based work attitudes. 


\section{DRIVER TURNOVER AND JOB-INDUCED TENSION}

Rhoades et al. (2001) confirmed this linkage empirically, finding that the effect of POS on turnover was fully mediated though affective commitment. Further, Allen et al. (2003) found that commitment and job satisfaction fully mediated POS effects on turnover. Thus, it appears that POS may be a more distal antecedent in the turnover process. However, based on the tenets of social exchange and reciprocity theory, receiving support from the organization should also cause some experienced obligation to the organization (e.g., Meyer \& Allen, 1991; Rhoades et al., 2001). Therefore, this study argued that POS, through the norm of reciprocity, can engender employee obligation to aid the organization. Further, with reciprocity comes increased commitment and decreased turnover. Yet, POS failed to show a direct relationship with turnover in this sample. It may be that there are underlying mechanisms such as commitment or job satisfaction that this study did not measure. For example, in a study of truck drivers, Ring (2010) found that POS was a mediator in the relationship between safety climate and voluntary turnover but this relationship differed by organizational tenure. That is, individuals early or late in their career found safety to be highly important and there was no support for the relationship of POS on turnover. Conversely, for those in the middle of their career POS was an important predictor of turnover. Tenure was highly correlated with turnover in this sample and was included as a control variable this could have masked the importance of tenure on POS perceptions in this sample.

Furthermore, the theory underlying the development of POS emphasizes discretionary behavior. The extent to which an organizational practice is seen as 


\section{DRIVER TURNOVER AND JOB-INDUCED TENSION}

discretionary influences the attributions that employees make about the organization's underlying motivation. More discretionary practices are more likely to be viewed as indicating support on the organization's part (Eisenberger et al., 1997). It is possible that, although, POS was relatively high in this sample $(M=5.04)$ that this support was not seen as discretionary and the mechanisms of reciprocity were compromised.

This study also failed to show support for the hypothesis regarding LMX and turnover. It was argued that LMX theory, which explicates the specific factors that play a role in determining the quality of supervisory-subordinate relations, would describe the supervisory behaviors that affect turnover (Gaertner, 1999). Meta-analytic findings indicate that the quality of LMX is negatively related to intended turnover (Gerstner and Day, 1997) and actual turnover (Dulebohn et al., 2012). But this relationship may be more complex than originally proposed. In a study of truck drivers, Morrow et al. (2005) found no relationship between organizational commitment and turnover. They indicate that organizational commitment may be a less potent predictor of turnover when alternate jobs are readily available and they recommended the examination of non-attitudinal causes of turnover. Williams, Garver, and Taylor (2011) utilizing a SET framework in an attempt to understand truck driver retention by examining driver values found that the most important factors in determining whether a driver stays with a firm are pay, personal safety, and time home. This study's finding reflects the majority of the research on truck driver retention by highlighting pay and time home as predictors of turnover but moves beyond it to also indicate that these factors are reflective of the social exchange 


\section{DRIVER TURNOVER AND JOB-INDUCED TENSION}

relationships within the organization. Thus, as Morrow et al. (2005) argue the highturnover environment inherent in the truck driving industry may indicate the importance of non-attitudinal causes of turnover but that there is value in examining social exchange relationships as the framework that is indicative of the value of these non-attitudinal causes. That is, there is reason to believe that important HR functions such as pay and scheduling are predictive of the perception that the organization values the employee (Shaw et al., 2004; Wayne et al., 1997) and that these HR functions may be more predictive of turnover in high-turnover occupations. As such Morrow et al. found a curvilinear relationship between LMX and turnover. The authors argue that with the shortage of drivers that good ones with strong skill sets are easily recruited by competing trucking firms thus good drivers are essentially pulled out of the organization (Harris et al., 2005). Therefore, it is possible that LMX is not linearly related to turnover or that these relationships are more complex in the trucking industry and it may be this complexity that was under-examined in the current study.

POS and LMX on job-induced tension. The relationship between POS, LMX, and turnover is cemented in the SET framework and is contingent on the norms of reciprocity. The relationship between POS, LMX, and job-induced tension utilizes the COR framework to characterize these relationships as resources that mitigate the effects of job demands. As such, this study provides evidence that there are negative relationships between POS, LMX, and job-induced tension and does so in an industry rarely studied by POS and LMX researchers. It was argued that perceptions of POS are important 


\section{DRIVER TURNOVER AND JOB-INDUCED TENSION}

resources (Hobfoll, 1989) that could bolster employees' confidence in their ability to cope with job demands (Lazarus, 1991). Armeli et al. (1998) maintain that POS meets a variety of socioemotional needs within the employer/employee relationship. Therefore, it was posited that employees who perceive that their organization cares about them and is genuinely interested in their well-being are likely to experience lower levels job-induced tension. This finding corroborates findings about the effects of POS and burnout (Cropanzano, Howes, Grandey, and Toth (1997, Study 2) indicating support for the assumption that POS is a resource that has potential to mitigate work demands and stress (Hobfoll, 1989).

Research on social support theory (e.g., Viswesvaran, Sanchez, \& Fisher, 1999) has suggested that support in various forms can act as a buffer against negative workplace outcomes (Ganster, Fusilier, \& Mayes, 1986; Parasuraman, Greenhaus, \& Granrose, 1992). Although general workplace social support has received the most research attention, the focus of this study is to examine when employees are strained but receive support from their supervisors and how this can minimize the negative personal impact of job strains (e.g., Harris \& Kacmar, 2005). COR theory suggests that job stressors will lead to less adverse outcomes (e.g., turnover, job-induced tension) when supervisors provide support that helps to minimize resource losses. Therefore, employees with high LMX relationships are not only more capable to cope with resource loss but are beneficiaries to resource gain in the form of increased social support, favorable treatment, 


\section{DRIVER TURNOVER AND JOB-INDUCED TENSION}

and higher levels of organizational information that is a result of LMX. Accordingly, these findings support the resource perspective of LMX on job-induced tension.

Dispatcher communication effectiveness. This study proposed that when one has weak social exchange relationships with their organization or supervisor that the quality of the interactions with the dispatcher would act as a buffer. In particular, dispatcher communication effectiveness would moderate the negative relationships between POS, LMX, turnover and job-induced tension. There was no support for the buffering effects of dispatcher communication effectiveness on the POS, LMX, and turnover relationships. Further, there was no support for the moderating effects of dispatcher communication effectiveness on the POS to job-induced tension relationship. There was, although, marginal support for the moderating effects of dispatcher communication effectiveness on the LMX to job-induced tension relationship.

An assumption inherent in this study is that drivers actually voice their concerns yet I did not measure voice levels. There is a body of research that indicates that POS may be related to voice behavior (Eisenberger et al., 2001; Ohly, Sonnentag, \& Pluntke, 2006). Furthermore, there is empirical research to suggest that an employees' evaluation of their status within the work group is predictive of their voice behavior (e.g., Tyler $\&$ Blader, 2003). This research has shown that the more employees perceive their supervisors to be responsive to their voice input, the more likely they are to engage in subsequent voice behavior (Saunders, Sheppard, Knight, \& Roth, 1992). Therefore, it could be posited that when POS and LMX relationships are weak the driver would 


\section{DRIVER TURNOVER AND JOB-INDUCED TENSION}

restrict their voice behavior. Thus, the dispatcher would only have opportunities to demonstrate communication effectiveness for those drivers that have strong POS and LMX relationship which would not capture any buffering effects proposed in this study.

This concern is slightly assuaged by the finding that dispatcher communication effectiveness moderated the relationship between LMX and job-induced tension. The graphical representation of the interaction appears to suggest that job-induced tension is the highest under conditions when LMX and dispatcher communication effectiveness are low. Although this result is to be interpreted with caution due to the non-significant simple slope analysis this finding may be indicative of the important role of the dispatcher. Further, upon examination of the regression equations it appears that dispatcher communication effectiveness may be driving the significance of the interaction. That is, the beta weight for dispatcher communication effectiveness is still significant when it is in the regression equation with LMX and the interaction term (Table 9). This may indicate that this study undervalued the role of the dispatcher.

\section{Theoretical Implications}

This study provides direct support for the idea that relationships matter regardless of the context. That is, by examining these relationships in an occupation where the majority of employees' time is spent unsupervised and away from the organization this study suggests that POS and LMX are important constructs with utility across contexts. By integrating COR theory the results of this study have conclusive ramifications as to the effects of high quality LMX relationships and their direct associations with employee 


\section{DRIVER TURNOVER AND JOB-INDUCED TENSION}

job-induced tension. Members of the in-group are statistically more likely to report lower levels job-induced tension. Conversely, the implications of this discovery may also indicate that LMX may actually contribute to a potential downward spiral for other direct reports. That is, LMX differentiation may be resource gain for some employees but a resource loss for others (e.g., Hooper \& Martin, 2008).

\section{Practical Implications}

Valuing employees' contributions, acting in their best interests, showing concern, and helping employees when they need help the most are some ways to enhance employees' perceptions of organizational support (Rhoades \& Eisenberger, 2002). By improving organizational support organizations can mitigate job-induced tension. The results of this study indicate that managers have three levers though which to increase support; senior management, the supervisor, or the dispatcher.

Management could increase POS whereas; supervisors could create high quality relationships with drivers as a means reducing job-induced tension. Organizations could show concern for employees' opinions and show pride in the accomplishments of their employees to demonstrate organizational support. In order to increase POS managers must strive to find out whether task-based or socioemotional needs are best targeted through support (e.g., Rhoades et al., 2001) and tailor support accordingly. Targeted efforts and policies to improve support in this way, and to publicize these efforts, could play a part in reducing employee job-induced tension (Cropanzano et al., 1997). For 


\section{DRIVER TURNOVER AND JOB-INDUCED TENSION}

example, senior management could signal that support is available with communicated public displays of management's concern for their employees' welfare.

This study illuminates the direct role that supervisors play in reducing jobinduced tension. Leaders within an organization should proactively gauge and monitor the LMX relationship within the workplace and better identify those direct reports who either belong to the out-group or who are on the cusp of such. At which point, supervisors should exert greater effort to establish an improved LMX relationship with their direct reports and counteract any existing conditions which might set in motion the workplace tension. Alternatively, although it has been suggested that LMX differentiation may be a resource gain for some and resource loss for others, there is research to indicate that the effects of LMX differentiation can be mitigated by perceived justice (Erdogan \& Bauer, 2010). Thus supervisors are encouraged to be fair in their decision making. Managers who are unable or unwilling to employ effective intervention on behalf those direct reports in need of emotional support should perhaps be considered for non-managerial roles within their organizations. Furthermore, organizations through trainings, could provide supervisors guidance on how to fine-tune their skills in trying to create highquality exchanges with their subordinates

A dispatcher that is empathetic to driver concerns is in the position to intervene when a driver is experiencing job-induced tension. Therefore, it becomes important to train dispatchers the necessary skills needed to resolve driver concerns and then to provide dispatchers with ongoing evaluations that include indicators of driver satisfaction 


\section{DRIVER TURNOVER AND JOB-INDUCED TENSION}

(Taylor, 1991). Human resource managers could recruit and select dispatchers that display responsive characteristics in order to address driver turnover and job-induced tension.

Finally, the control variables used in this study point to driver differences that may be indicative of turnover. There were significant bivariate correlational relationships between tenure and turnover as well as with the driver's number of previous employers and turnover. In particular, this study found a positive relationship between number of previous employers and turnover suggesting that the more employers a driver has the more likely the driver is to leave the organization. This is consistent with what has been termed the hobo syndrome (Judge \& Watanabe, 1995) that states that some workers have internal impulses to migrate from one job to another regardless of better alternatives or other rational reasoning. Thus, an increased number of previous employers may indicate a propensity to turnover. Conversely, organizational tenure was negatively correlated to turnover suggesting that the longer a driver is with an organization the less likely they are to leave the organization. This is consistent with job embeddedness (Mitchell et al., 2001) in that increased tenure with an organization may come with increased salary, benefits, and social relationships that would then be lost or sacrificed should the driver leave the organization. These relationships suggest that trucking organizations should consider number of previous employers and previous organizational tenure in their selection decisions. That is, an increased number of previous employers and a lack of organizational tenure should be used to make screening decisions in the selection process. 


\section{DRIVER TURNOVER AND JOB-INDUCED TENSION}

\section{Study Limitations}

This study suggests that both types of exchanges (i.e., LMX and POS) are important and influential in predicting job-induced tension which provides evidence of the distinctiveness of POS and LMX. This would indicate that drivers can distinguish between exchanges with leaders and with their organizations. However, there is research indicating that LMX plays a key role in affecting employees' perceptions of organizational support (Wayne at al., 1997) that is because the leader is often the source or distributor of rewards provided by an organization. Thus, the exchange relationship between the leader and subordinate may influence POS. Supervisors often play a role in determining salary increases as well as task and training opportunities, emotional support, and information. Therefore, the nature of the LMX relationship may directly and indirectly influence the perception of POS. Furthermore, although dispatchers often supervise the operational responsibilities of the driver the dispatcher may not be the immediate supervisor of the driver (Fournier, Lamontagne, \& Gagnon, 2012). Yet given that the dispatcher is the primary organizational contact to the driver, it stands that a number of attributes about the organization may be formed through the interactions between the driver and the dispatcher (Richard et al., 1994). Therefore, the nature of the relationship with one's dispatcher may influence the perceptions of LMX and POS. This may be why these three variables were so highly correlated in this study. This study makes it difficult to ascertain which of these variables may be more important in predicting job-induced tension. Although statistically POS appeared to have a stronger 


\section{DRIVER TURNOVER AND JOB-INDUCED TENSION}

relationship with job-induced tension, it is unclear how the perception of POS in the driver came to be. This makes it difficult to target future trainings or interventions.

Furthermore, there are a couple of design limitations that must be noted. First, this study utilized a time-lagged design to address turnover, but due to organizational constraints the hypotheses regarding job-induced tension were collected with a crosssectional design. The cross-sectional nature of these data prevents inferences of causality. It is quite possible that employees experiencing job-induced tension are less likely to take part in the exchanges necessary to create a relationship with their organization or their supervisor.

Another potential limitation is sample size. It is difficult to detect effects in a sample of 166 participants. Although I found support for the main effect relationships examining job-induced tension and marginal support for a 2-way interaction, it is difficult to establish whether lack of support for the other hypothesized interactions is because of a true lack of relationships or because of insufficient statistical power to detect small effects. For example, according to Long (1997), 100 is a minimum sample size for logistic regression, with at least 10 observations per predictor. In this study there were 166 participants but only 60 left the organization voluntarily and only 28 of these provided survey results. This provides just 10 observations in the category "leaver" per hypothesized predictor (i.e., not including control variables). Furthermore, an a priori power analyses demonstrated that a minimum sample of 343 was needed to capture enough power to detect effects in the proposed relationships. This power analyses was 


\section{DRIVER TURNOVER AND JOB-INDUCED TENSION}

conducted considering the complexity of the originally proposed mediated moderation model. A post hoc analysis was conducted to lessen the constraints of the analysis based on the new less complex model and reveals that with power at .80 a sample size of 172 was required to detect the moderating relationships. Further, interaction effects are very difficult to detect with a small sample size (Aiken \& West, 1991) thus my sample size may have been a limiting factor in determining the relationships in this study.

\section{Future Research}

This study illuminates numerous future research opportunities. First, while the relationship between POS and employee well-being has received empirical attention little research has been conducted examining the mechanisms underlying this relationship (Baran et al., 2012). This study theorizes that POS is a resource through which an employee can draw to allay themselves to the stressors inherent in the truckload carrier occupation. POS theory would maintain POS is contributing to greater physical and psychological well-being because the socioemotional support function of POS meets needs for esteem, affiliation, and emotional support. Future research should consider examining these mediating mechanisms as potential resources. Furthermore, given the nature of this study's context drivers rarely interact with their supervisor; thus the opportunity to form a high quality LMX relationship is hindered. Future research could examine how LMX relationships form across time and across contexts. For example, it is possible that limited interaction time between supervisor and subordinate speeds or slows 


\section{DRIVER TURNOVER AND JOB-INDUCED TENSION}

the formations of the LMX relationship. Longitudinal designs would further support the findings of this study by examining the exchange process across time.

Furthermore, there are contextual reasons why this study's hypotheses may have been unsupported. The participants in this sample were employed in a moderate sized trucking organization where driver routes were comparatively short. Drivers, on average, were home every three days and enjoyed relatively short dispatcher miles compared to industry standards. These organizational factors may have decreased overall turnover. Future research should collect data from a variety of trucking firms to ascertain the nature of turnover and social exchange relationships. Related, although the trucking industry is experiencing a driver shortage this data was collected during an economic downturn. Conversations with the organizational partners indicated that they were receiving a record number of applicants. It may very well be that those drivers with weak social exchange relationships were delaying their organizational exit due to concerns of alternative opportunities. As such, it may have been more fruitful to predict and examine the attitudinal predictors of turnover such as turnover intentions. With this in mind, post hoc analyses were conducted to ascertain the relationships between POS, LMX, and turnover intentions. The results indicate that both POS and LMX were significantly related to turnover intention at the .01 level. Future work in this area should provide theoretical justification for these relationships and investigate this in greater depth.

Overall, this study adds to our understanding of driver turnover and job-induced tension and contributes to the current state of the literature. Yet, as with any study there 


\section{DRIVER TURNOVER AND JOB-INDUCED TENSION}

are a few things I would have done differently. First, I argued that it was possible that drivers failed to exhibit voice behavior due to weak POS and LMX relationships but this assumption has yet to be tested empirically. Future research should measure both quality and quantity of a driver's voice behavior to ascertain the mechanisms in play between POS, LMX, and the dispatcher communication effectiveness.

Finally, turnover and job-induced tension were selected as the outcome variables in this study due to context in which this study took place. The trucking industry is facing an epidemic driver shortage and it is well-established that drivers face a host of job stressors. While this study design did not allow the collection of physical markers of stress this would have ideally been more telling to the impact of social exchange relationships on job-induced tension. For example, Du, Lin, Lu, and Tai (2011) in a study of bus drivers examined the effects of the relationship one has with their supervisor as predictor of urine cortisol levels. The inclusion of biomarkers of stress may allow for a more complete picture of the myriad of potential stressors in the trucking industry and a more complete picture of the outcomes associated with these stressors. Future research is encouraged to examine both the perceptions of job-induced tension as it is here and the physical markers of work stress.

\section{Conclusion}

The aim of this study was to address the problem of turnover and job-induced tension in a truck-driving context. Results provide theoretical support for the view that POS and LMX are important determinants when considering job-induced tension. 


\section{DRIVER TURNOVER AND JOB-INDUCED TENSION}

Furthermore, results provide practical advice to trucking organizations as to the protective role of the dispatcher and importance that this role serves in the organization. 


\section{DRIVER TURNOVER AND JOB-INDUCED TENSION}

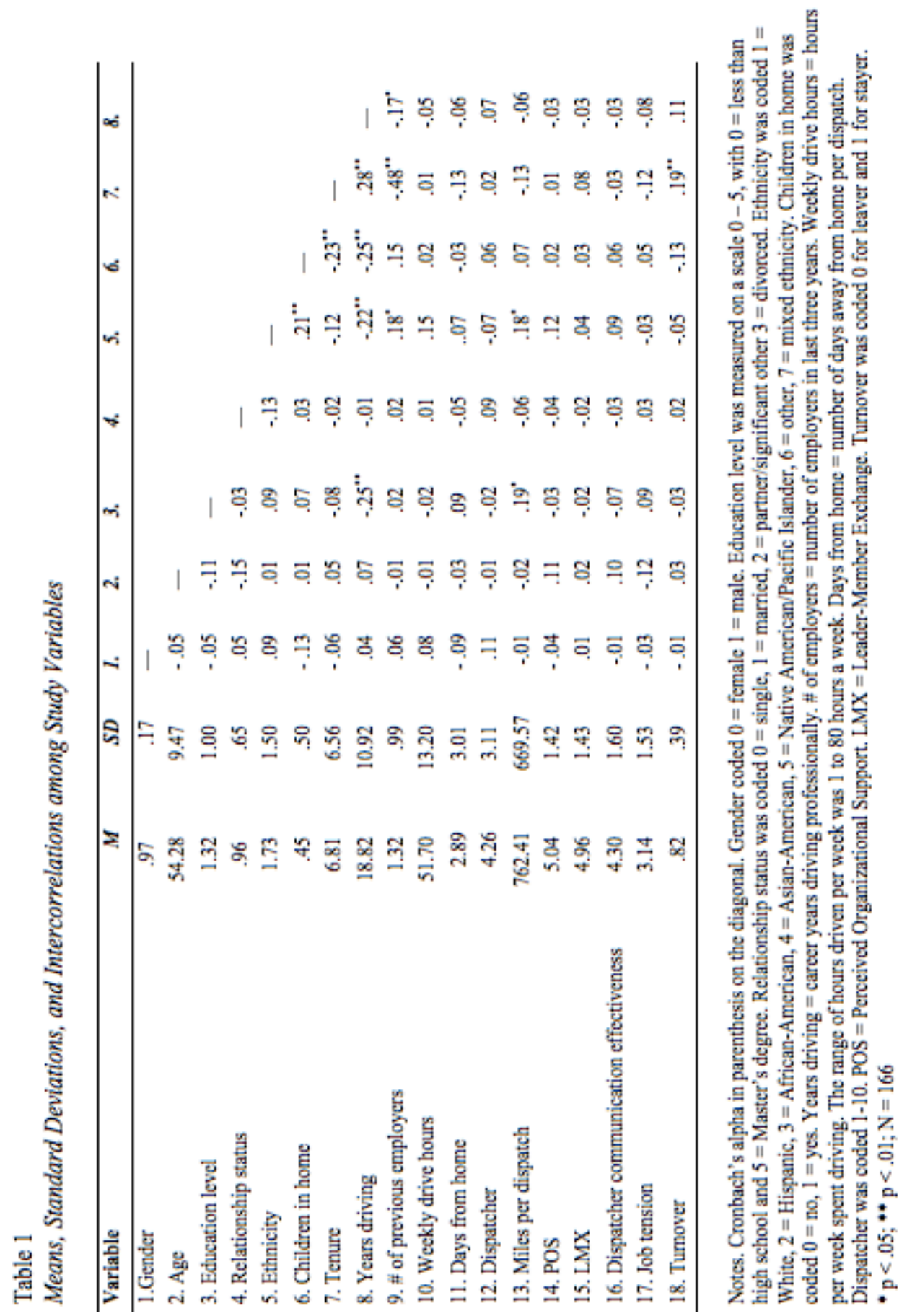




\section{DRIVER TURNOVER AND JOB-INDUCED TENSION}

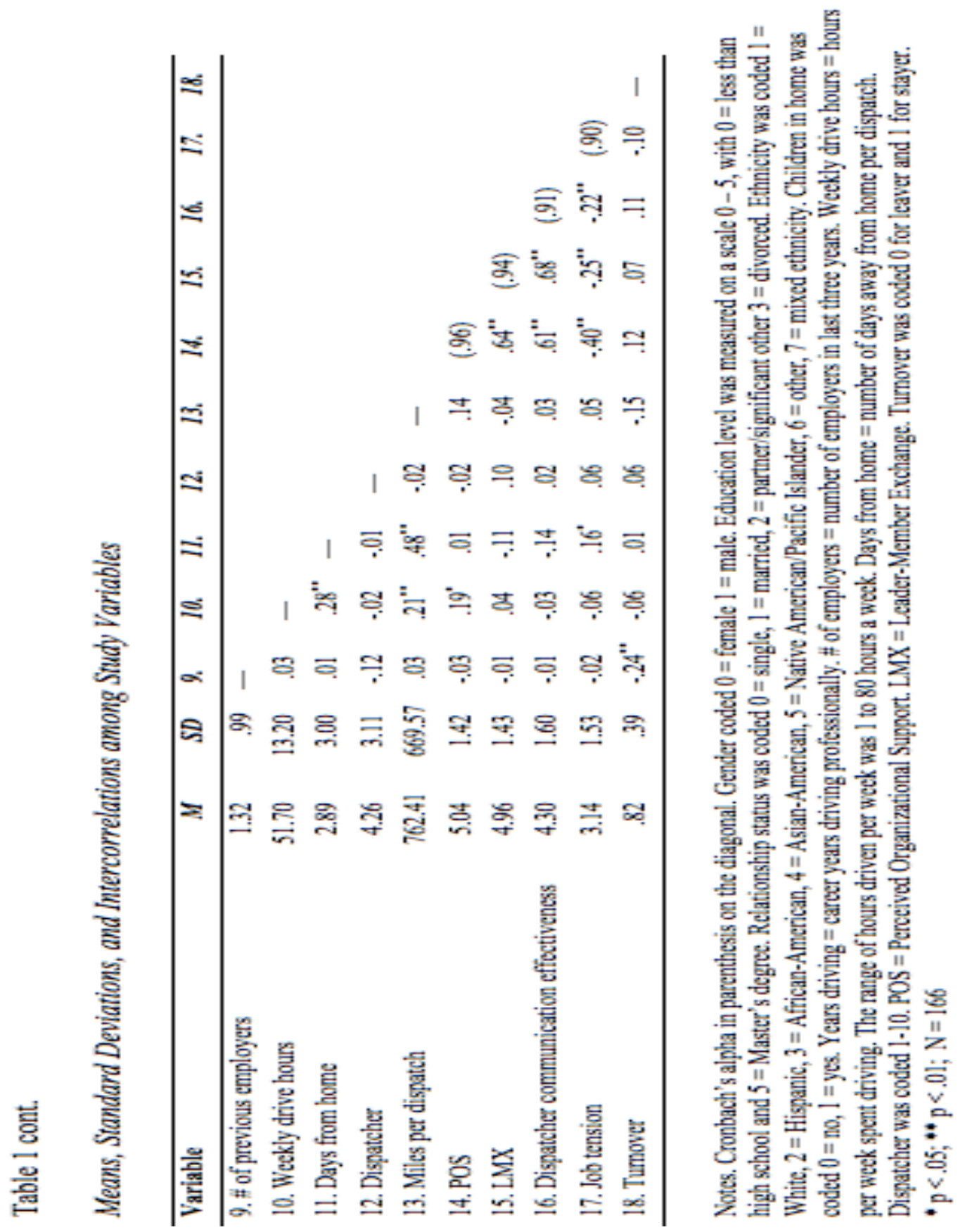




\section{DRIVER TURNOVER AND JOB-INDUCED TENSION}

\section{Table 2}

Summary of Study Changes and Overview of the Results of the Hypotheses

\begin{tabular}{llll}
\hline Hypotheses & \multicolumn{1}{c}{ Relationship } & \multicolumn{1}{c}{$\begin{array}{c}\text { Changes to } \\
\text { Hypotheses }\end{array}$} & \multicolumn{1}{c}{ Results } \\
\hline 1 & POS $\rightarrow$ turnover & No change & Not supported \\
2 & POS $\rightarrow$ tension & No change & No change \\
3 & LMX $\rightarrow$ turnover & No change & Not supported \\
4 & LMX $\rightarrow$ tension & Removed & - \\
$5,6,7,8, \mathrm{a}$ & Sensitivity to voice as moderator & - \\
$5,6,7,8, \mathrm{~b}$ & Sensitivity to voice $\rightarrow$ responsiveness & Removed & - \\
$5,6,7,8, \mathrm{c}$ & Dispatcher responsiveness as moderator & Removed & - \\
$5,6,7,8, \mathrm{~d}$ & Mediated moderation & Removed & - \\
$5 \mathrm{e}$ & DCE as moderator in POS $\rightarrow$ turnover & Added to study & Not supported \\
$6 \mathrm{e}$ & DCE as moderator in POS $\rightarrow$ tension & Added to study & Not supported \\
$7 \mathrm{e}$ & DCE as moderator in LMX $\rightarrow$ turnover & Added to study & Not supported \\
$8 \mathrm{e}$ & DCE as moderator in LMX $\rightarrow$ tension & Added to study & Moderate \\
& & & support \\
\hline
\end{tabular}

Notes: Changes to hypotheses occurred after it was determined that sensitivity to voice and dispatcher responsiveness had much better fit as one construct. The changed hypotheses retain the theorizing and intention of the study. POS = Perceived Organizational Support. LMX = Leader-Member Exchange. $\mathrm{DCE}=$ Dispatcher Communication Effectiveness, the created composite variable of sensitivity to voice and dispatcher responsiveness. 


\section{DRIVER TURNOVER AND JOB-INDUCED TENSION}

Table 3

Logistic Regression Analyses for Predicting Turnover with POS and LMX

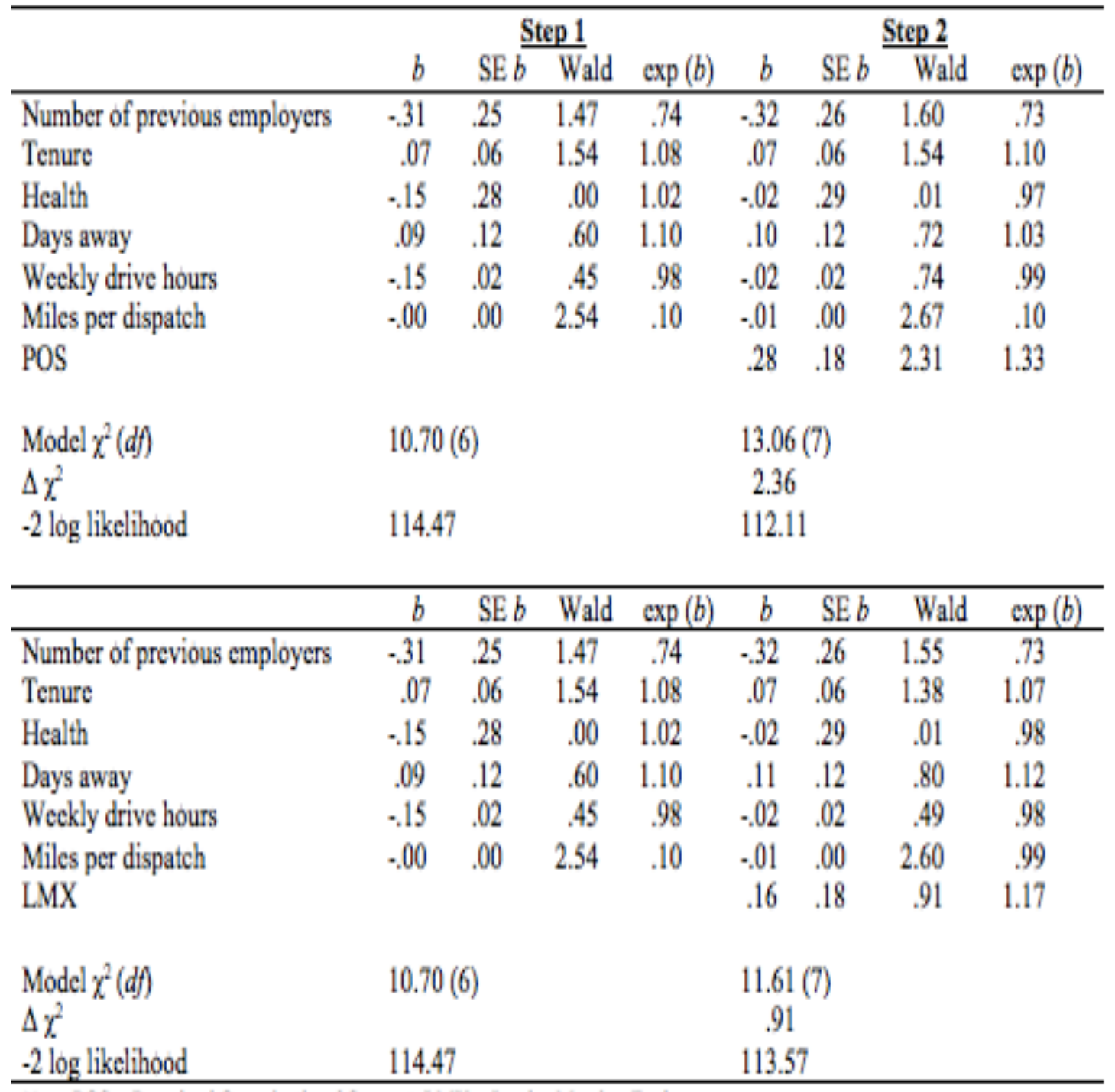

Note: POS - Perceived Organizational Support. LMX - Leader Member Exchange.

$" p<.05 ; " * p<.01 ; N=166$ 
DRIVER TURNOVER AND JOB-INDUCED TENSION

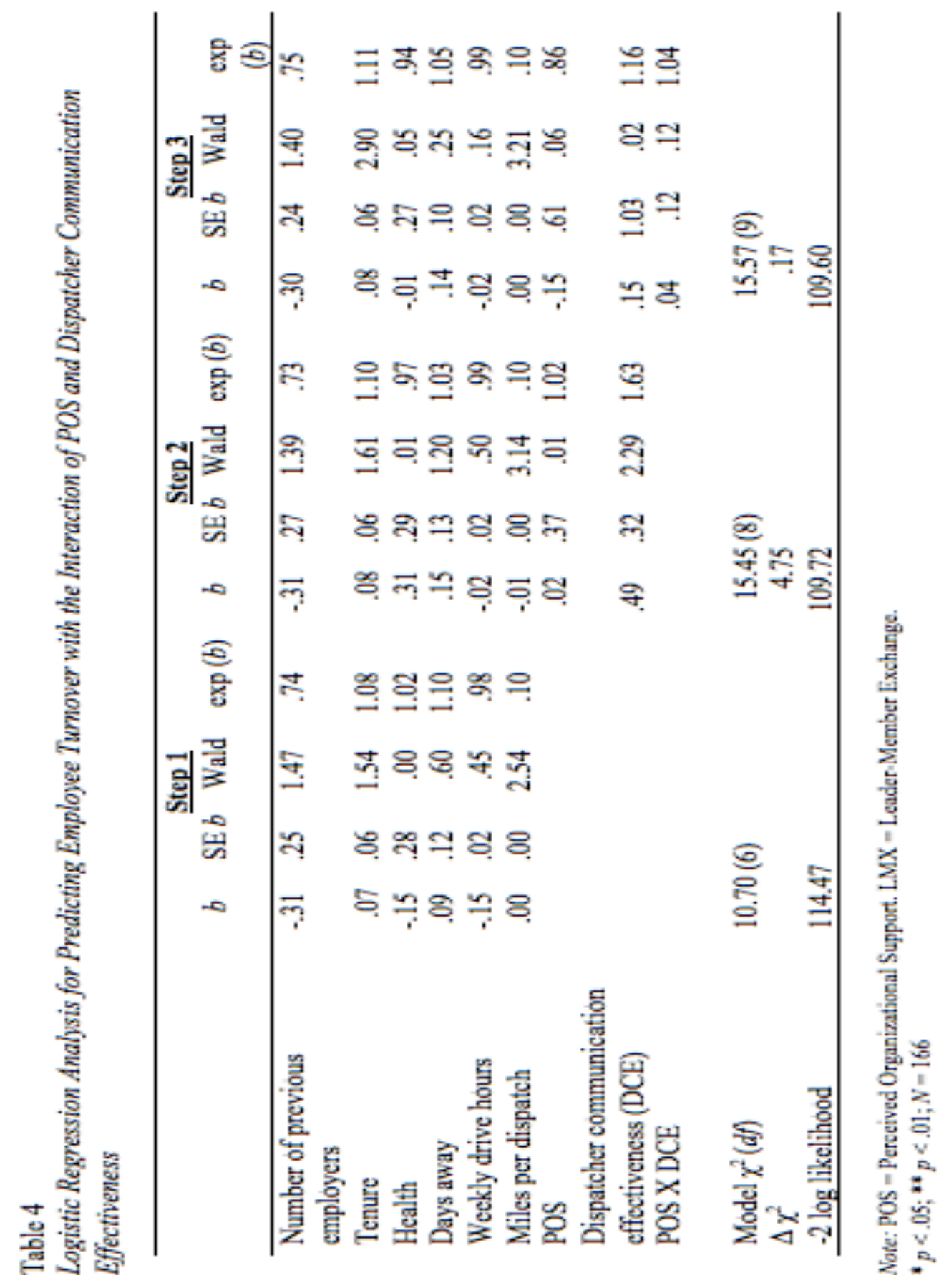


DRIVER TURNOVER AND JOB-INDUCED TENSION

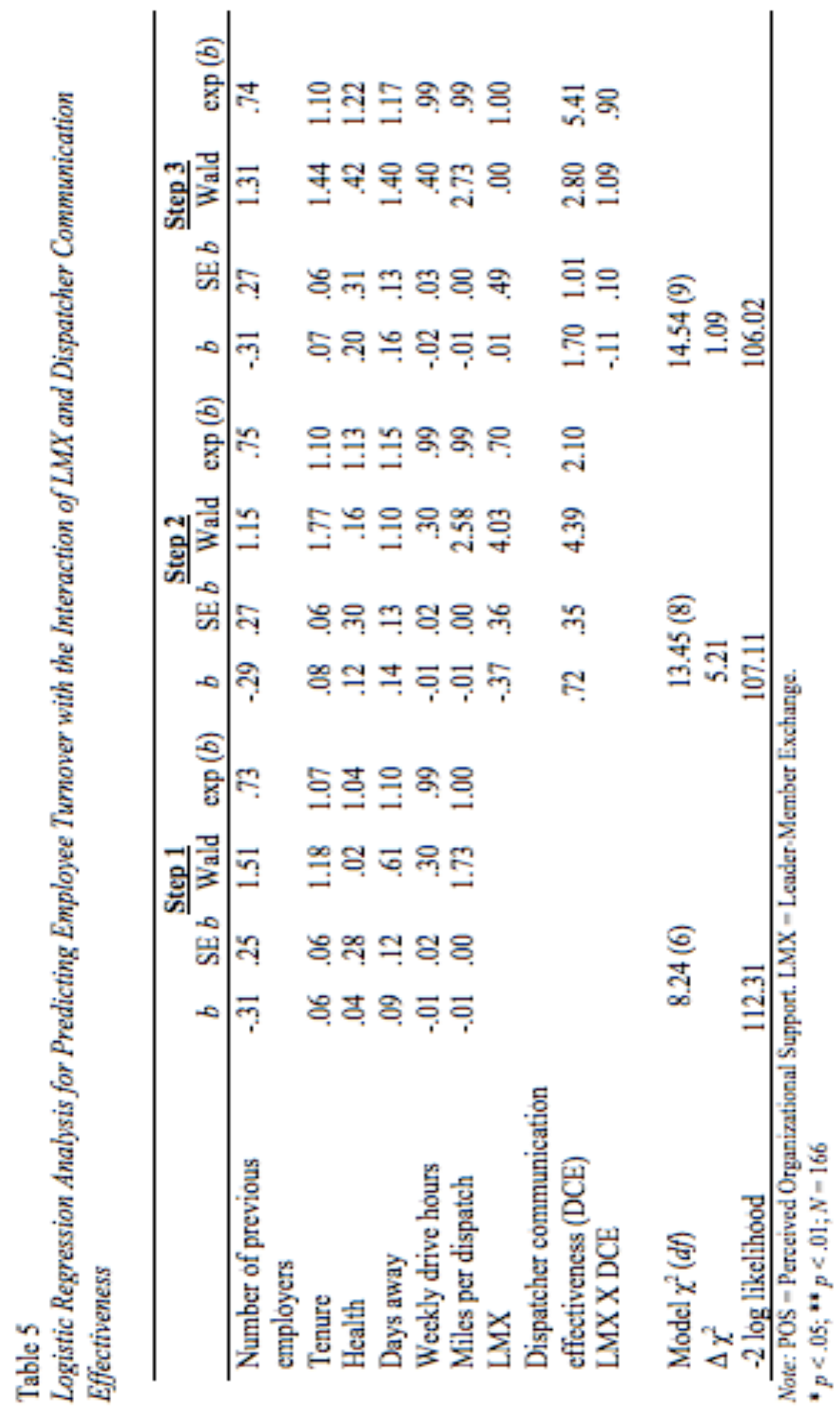




\section{DRIVER TURNOVER AND JOB-INDUCED TENSION}

Table 6

Hierarchical Multiple Regression Analyses Predicting Job Tension from POS and $L M X$

\begin{tabular}{|c|c|c|c|c|}
\hline & \multicolumn{4}{|c|}{ Job Tension } \\
\hline Predictor & $\beta$ & $\Delta R^{2}$ & $\beta$ & $\Delta R^{2}$ \\
\hline Step 1 & & $.12^{* *}$ & & . \\
\hline Weekly drive hours & -.03 & & .03 & \\
\hline Days from home & .16 & & .10 & \\
\hline Miles per dispatch & -.10 & & .05 & \\
\hline Health & $-.28^{* *}$ & & $-.26^{* *}$ & \\
\hline Step 2 & & & & $21^{* *}$ \\
\hline \multirow[t]{2}{*}{ POS } & & & $-.47^{* *}$ & \\
\hline & \multicolumn{4}{|c|}{$\underline{\text { Job Tension }}$} \\
\hline Predictor & $\beta$ & $\Delta R^{2}$ & $\beta$ & $\Delta R^{2}$ \\
\hline Step 1 & & $.12^{* *}$ & & \\
\hline Weekly drive hours & -.03 & & -.10 & \\
\hline Days from home & .16 & & .15 & \\
\hline Miles per dispatch & -.10 & & -.10 & \\
\hline Health & $-.28^{* *}$ & & $-.24^{* *}$ & \\
\hline Step 2 & & & & $.06^{* *}$ \\
\hline LMX & & & $-.27^{* *}$ & \\
\hline
\end{tabular}

Note $:$ POS $=$ Perceived Organizational Support. LMX = Leader-Member Exchange.

$* p<.05 ; * * p<.01 ; N=166$ 


\section{DRIVER TURNOVER AND JOB-INDUCED TENSION}

Table 7

Hierarchical Multiple Regression Analyses Predicting Job Tension from POS and the Interaction of POS and Dispatcher Communication Effectiveness

\begin{tabular}{|c|c|c|c|c|c|c|}
\hline & & & Job T & sion & & \\
\hline Predictor & $\beta$ & $\Delta R^{2}$ & $\beta$ & $\Delta R^{2}$ & $\beta$ & $\Delta R^{2}$ \\
\hline Step 1 & & $.12^{* *}$ & & & & \\
\hline Miles per dispatch & -.01 & & .05 & & .05 & \\
\hline Weekly drive hours & -.03 & & .04 & & .04 & \\
\hline Days from home & .16 & & .11 & & .10 & \\
\hline Health & $-.28^{* *}$ & & $-.26^{* *}$ & & $-.26^{* *}$ & \\
\hline Step 2 & & & & $.22^{* *}$ & & \\
\hline POS & & & $-.51^{* *}$ & & $-.50^{* *}$ & \\
\hline $\begin{array}{l}\text { Dispatcher communication } \\
\text { effectiveness (DCE) }\end{array}$ & & & .06 & & .05 & \\
\hline Step 3 & & & & & & .00 \\
\hline POS X DCE & & & & & .03 & \\
\hline
\end{tabular}

Note: POS $=$ Perceived Organizational Support. LMX = Leader-Member Exchange.

$* p<.05 ; * * p<.01 ; N=166$ 


\section{DRIVER TURNOVER AND JOB-INDUCED TENSION}

Table 8

Hierarchical Multiple Regression Analyses Predicting Job Tension from LMX and the Interaction of LMX and Dispatcher Communication Effectiveness

\begin{tabular}{|c|c|c|c|c|c|c|}
\hline & & & Job T & ion & & \\
\hline Predictor & $\beta$ & $\Delta R^{2}$ & $\beta$ & $\Delta R^{2}$ & $\beta$ & $\Delta R^{2}$ \\
\hline Step 1 & & $.12^{* *}$ & & & & \\
\hline Miles per dispatch & .02 & & .05 & & .04 & \\
\hline Weekly drive hours & -.03 & & -.02 & & -.01 & \\
\hline Days from home & .16 & & .11 & & .10 & \\
\hline Health & $-.27^{* *}$ & & $-.25^{* *}$ & & -.27 & \\
\hline Step 2 & & & & $.09^{* *}$ & & \\
\hline LMX & & & -.08 & & -.06 & \\
\hline $\begin{array}{l}\text { Dispatcher communication } \\
\text { effectiveness (DCE) }\end{array}$ & & & $-.25^{*}$ & & $-.24^{* *}$ & \\
\hline Step 3 & & & & & & $.02^{\dagger}$ \\
\hline LMX X DCE & & & & & .14 & \\
\hline
\end{tabular}

Note: $\mathrm{POS}=$ Perceived Organizational Support. LMX = Leader-Member Exchange.

$* p<.05 ; * * p<.01, \dagger$ denotes marginal significance $(p<.10) ; N=166$ 


\section{DRIVER TURNOVER AND JOB-INDUCED TENSION}

Figure 1

Conceptual Model

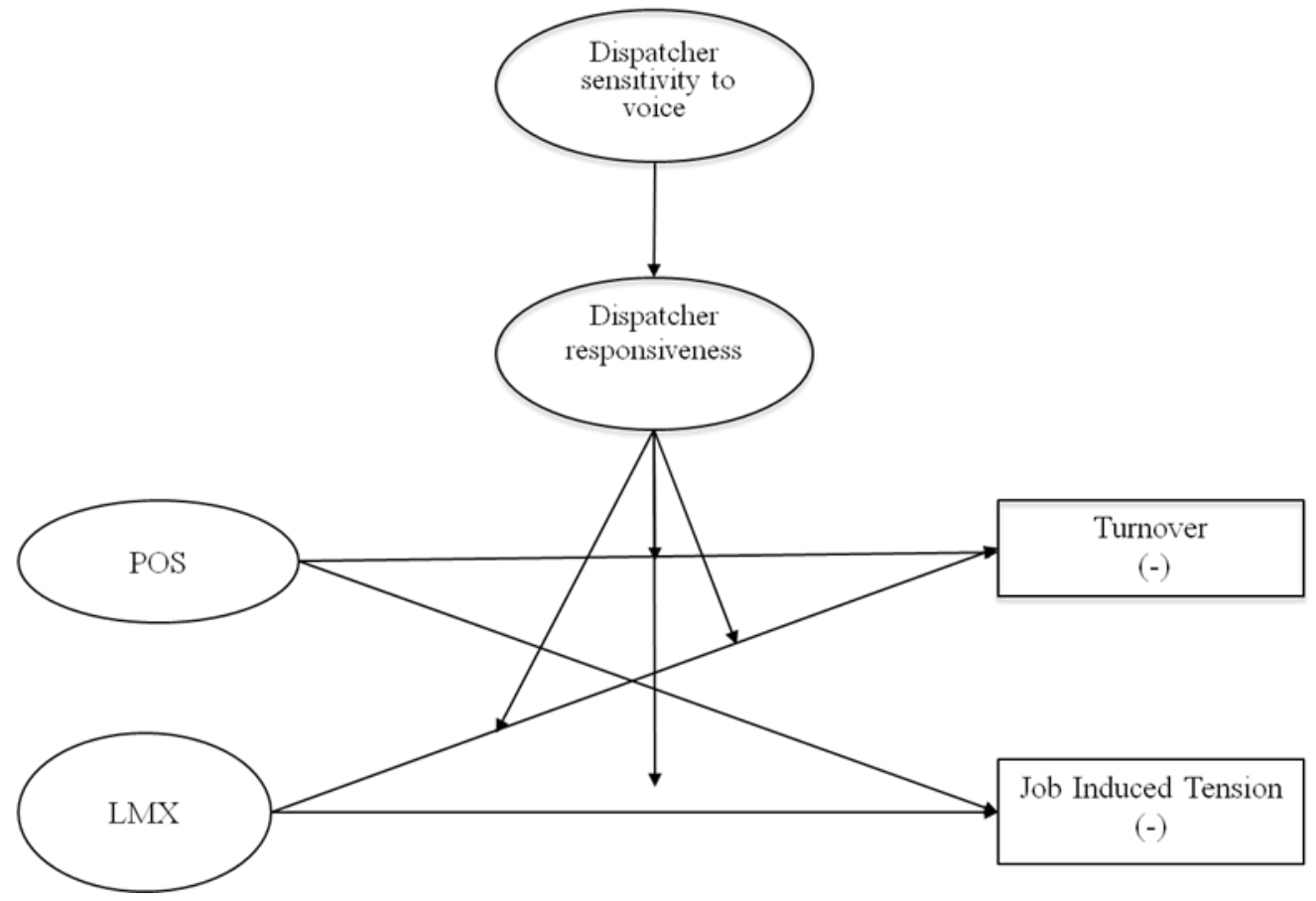




\section{DRIVER TURNOVER AND JOB-INDUCED TENSION}

Figure 2

Hypotheses 1-4

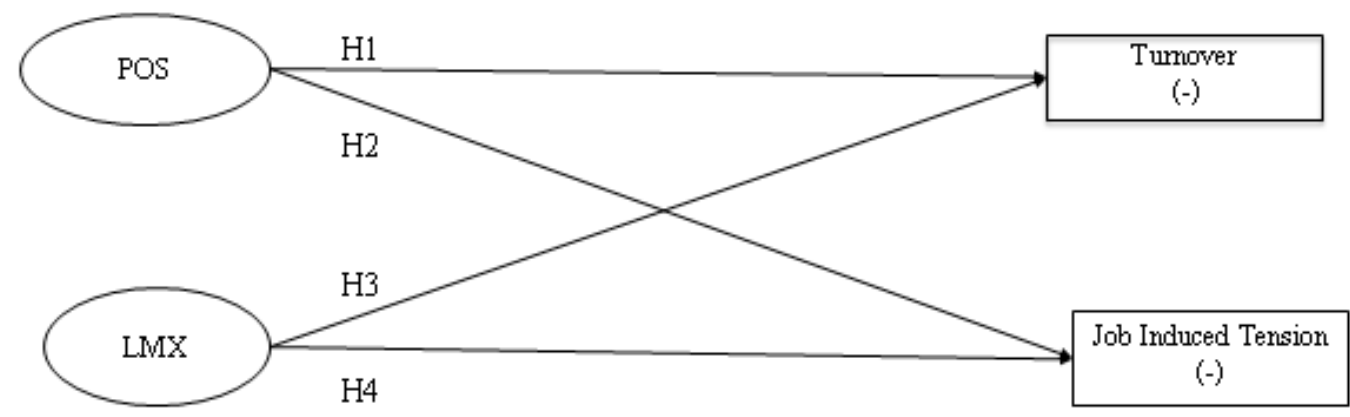




\section{DRIVER TURNOVER AND JOB-INDUCED TENSION}

Figure 3

Hypotheses 5a-d

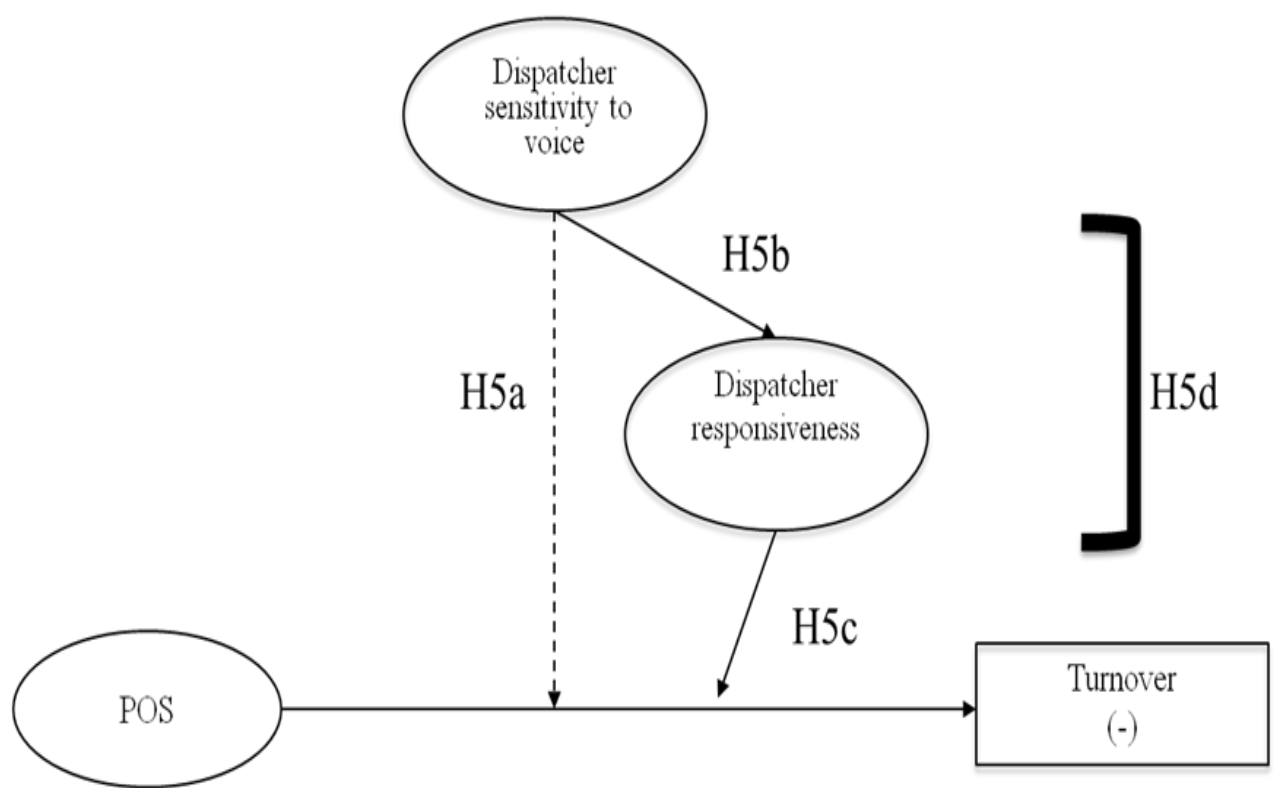




\section{DRIVER TURNOVER AND JOB-INDUCED TENSION}

Figure 4

Hypotheses 6a-d

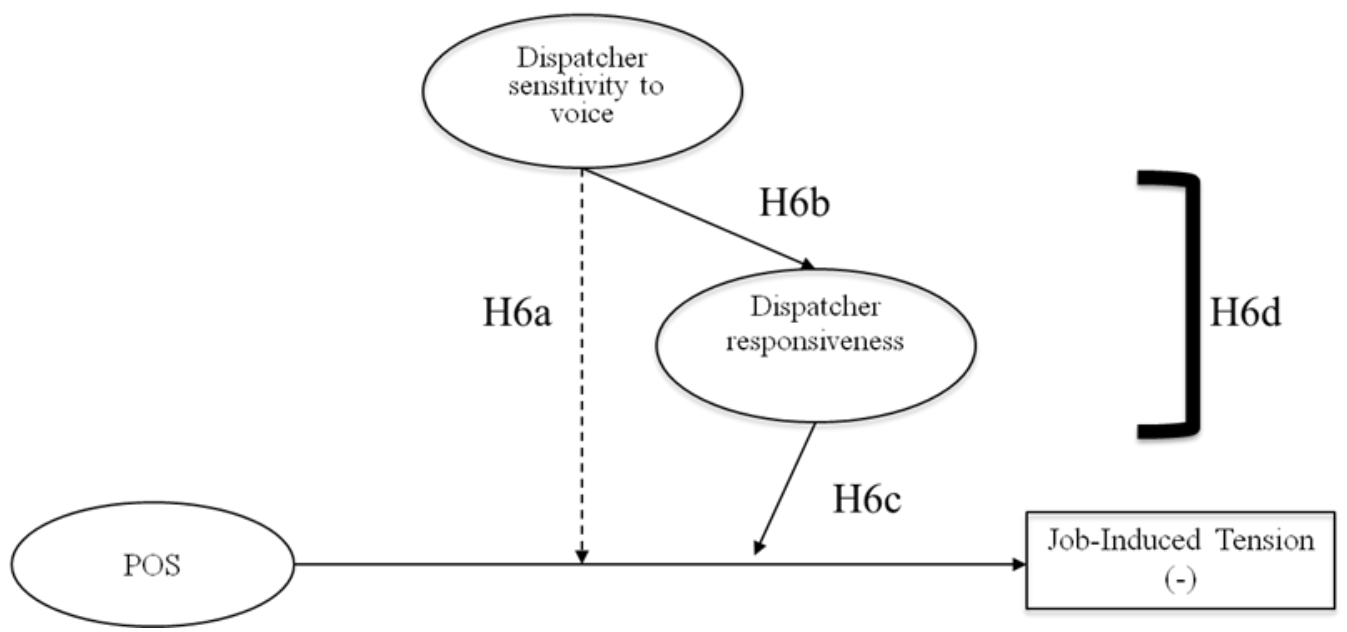




\section{DRIVER TURNOVER AND JOB-INDUCED TENSION}

Figure 5

Hypotheses 7a-d

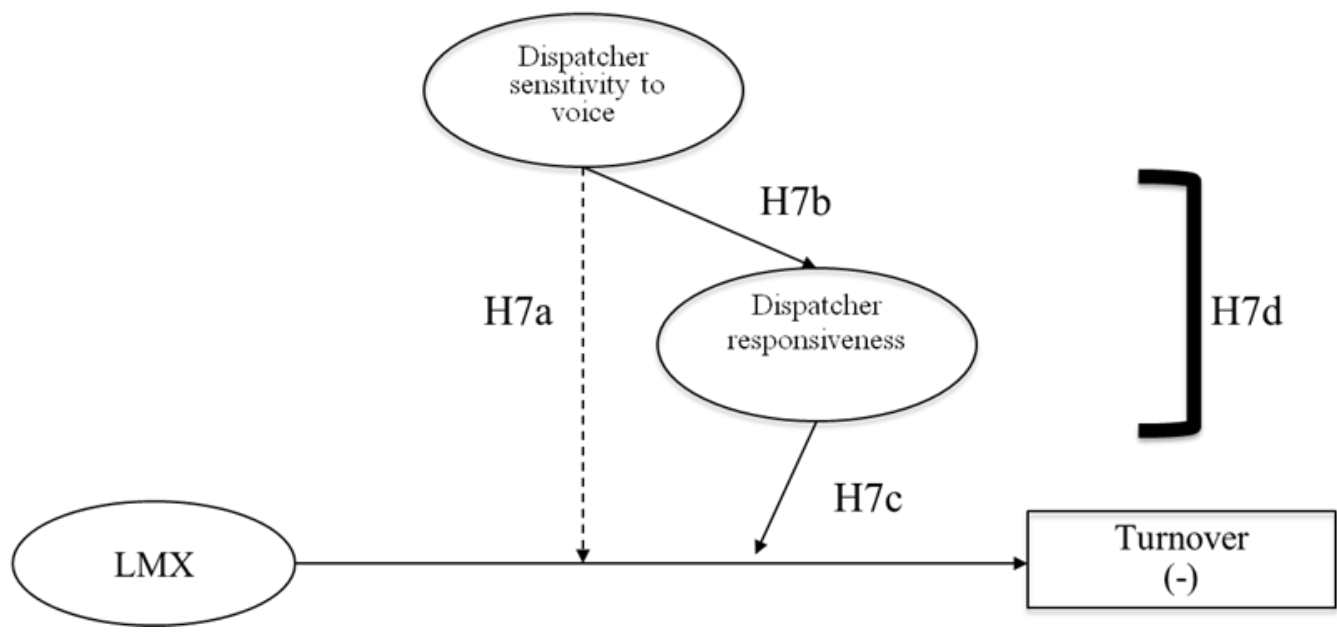




\section{DRIVER TURNOVER AND JOB-INDUCED TENSION}

Figure 6

Hypotheses $8 a-d$

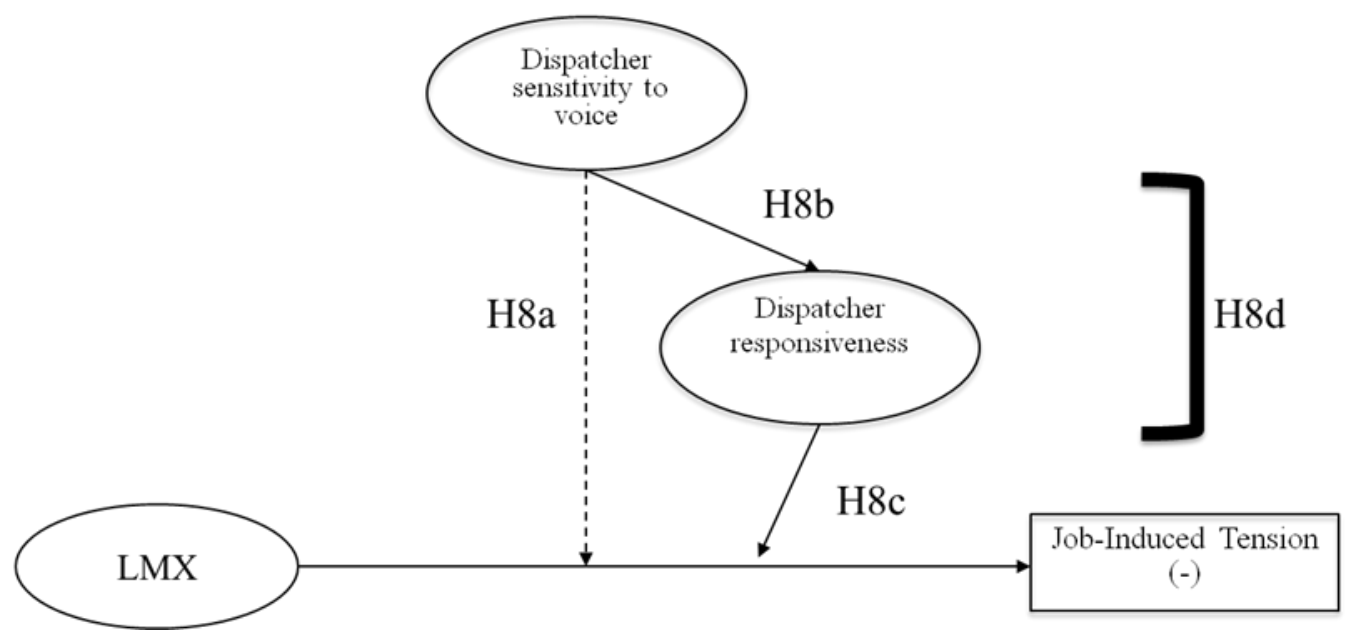




\section{DRIVER TURNOVER AND JOB-INDUCED TENSION}

Figure 7

Modified Model for Hypotheses 5 and 6 to Reflect the Composite Variable Dispatcher Communication Effectiveness

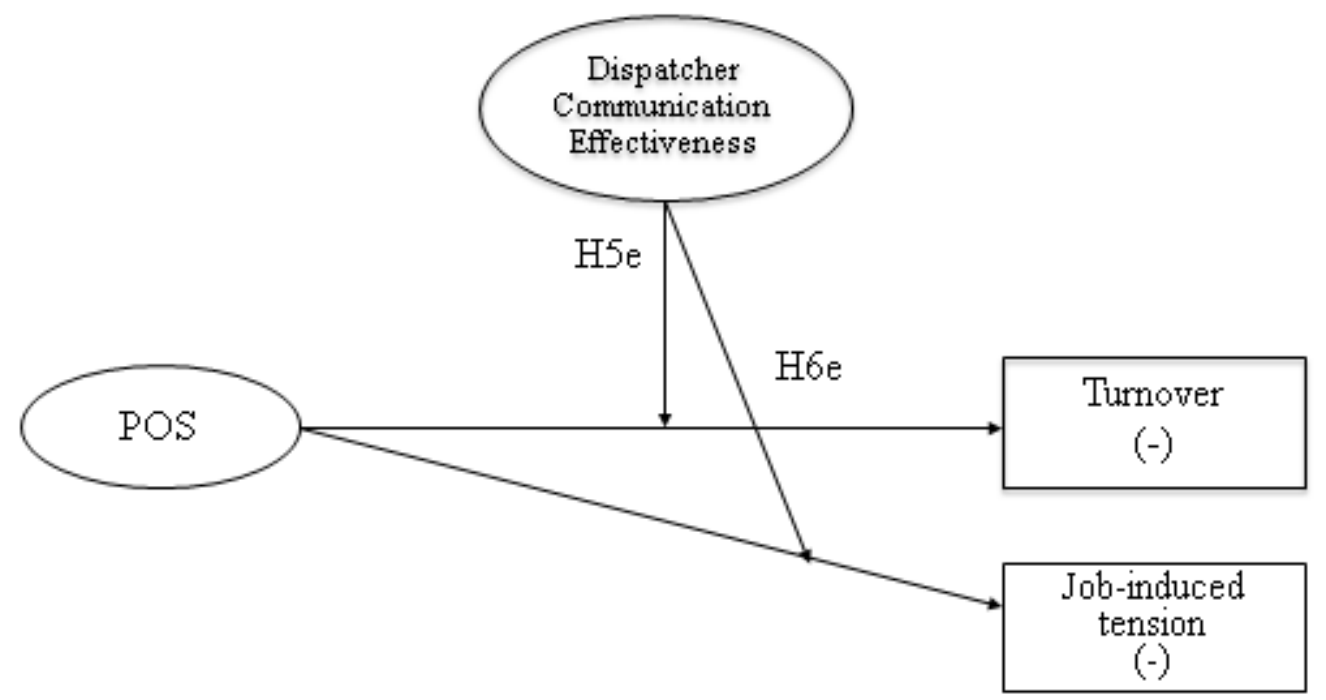




\section{DRIVER TURNOVER AND JOB-INDUCED TENSION}

Figure 8

Modified Model for Hypotheses 7 and 8 to Reflect the Composite Variable Dispatcher Communication Effectiveness

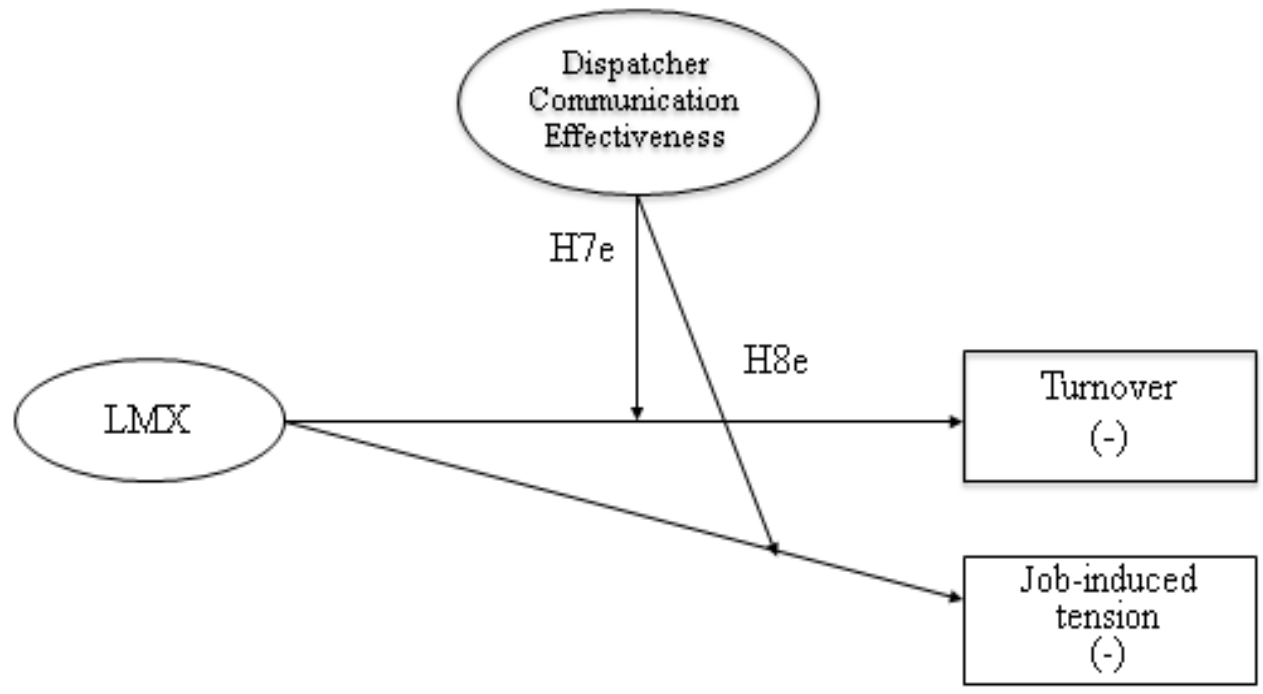




\section{DRIVER TURNOVER AND JOB-INDUCED TENSION}

Figure 9

Interaction between LMX and Dispatcher Communication Effectiveness on Jobinduced Tension

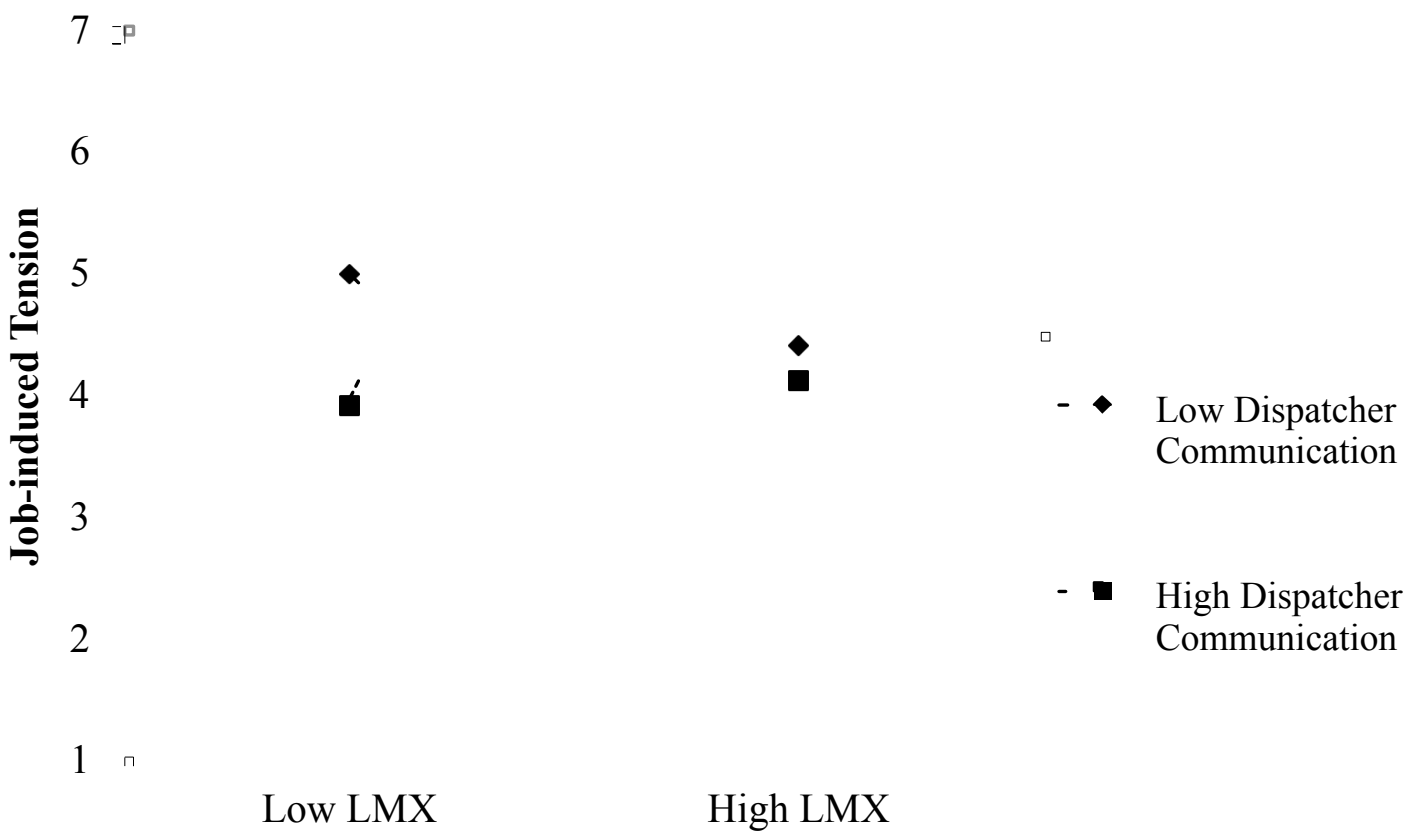




\section{DRIVER TURNOVER AND JOB-INDUCED TENSION}

\section{References}

Abelson, M. A. (1987). Examination of avoidable and unavoidable turnover. Journal of Applied Psychology, 72, $382-386$.

Adams, J. S. (1963). Towards an understanding of inequity. The Journal of Abnormal and Social Psychology, 67, 422-436.

Aiken, L. S., \& West, S. G. (1991). Multiple regression: Testing and interpreting interactions. Newbury Park, CA: Sage

Allen, D. G., \& Shanock, L. R. (2013). Perceived organizational support and embeddedness as key mechanisms connecting socialization tactics to commitment and turnover among new employees. Journal of Organizational Behavior, 34, 350-369.

Allen, D. G., Shore, L. M., \& Griffeth, R. W. (2003). The role of perceived organizational support and supportive human resource practices in the turnover process. Journal of Management, 29, 99-118.

Allen, D. G., Weeks, K. P., \& Moffitt, K. R. (2005). Turnover intentions and voluntary turnover: the moderating roles of self-monitoring, locus of control, proactive personality, and risk aversion. Journal of Applied Psychology, 90, 980 - 990.

American Trucking Associations (2012). Retrieved July 25, 2013 from http://www.truckline.com/News_and_Information_Reports_Industry_Data.aspx. 


\section{DRIVER TURNOVER AND JOB-INDUCED TENSION}

Anderson, D., \& Riley, P. (2008). Determining standards of care for substance abuse and alcohol use in long-haul truck drivers. Nursing Clinics of North America, 43, 357365.

Apostolopoulos, Y., Peachey, A. A., \& Sönmez, S. (2011). The psychosocial environment of commercial driving: Morbidities, hazards, and productivity of truck and bus drivers. Handbook of Stress in the Occupations, 431-447.

Apostolopoulos, Y., Sönmez, S., Shattell, M. M., Gonzales, C., \& Fehrenbacher, C. (2013). Health survey of US long-haul truck drivers: Work environment, physical health, and healthcare access. Work: A Journal of Prevention, Assessment and Rehabilitation, 46, 113-123.

Apostolopoulos, Y., Sönmez, S., Shattell, M. M., Rothenberg, R., Weitz, R., \& Smith, J. (2010). Infection risk along US highways? The case of a 'truckchaser'cruising for truckers. International Journal of Sexual Health, 22(4), 262-271.

Argyris, C., \& Schon, D. (1978). Organizational Learning: A theory of action approach. Reading, MA: Addision Wesley.

Armeli, S., Eisenberger, R., Fasolo, P., \& Lynch, P. (1998). Perceived organizational support and police performance: The moderating influence of socioemotional needs. Journal of Applied Psychology, 83, 288 - 297.

Baran, B. E., Shanock, L. R., \& Miller, L. R. (2012). Advancing organizational support theory into the twenty-first century world of work. Journal of Business and Psychology, 27, 123-147. 


\section{DRIVER TURNOVER AND JOB-INDUCED TENSION}

Barrick, M. R., \& Zimmerman, R. D. (2005). Reducing voluntary, avoidable turnover through election. Journal of Applied Psychology, 90, 159 - 166.

Bauer, T. N., Erdogan, B., Liden, R. C., \& Wayne, S. J. (2006). A longitudinal study of the moderating role of extraversion: Leader-member exchange, performance, and turnover during new executive development. Journal of Applied Psychology, 91, $298-310$.

Bauer, T. N., \& Green, S. G. (1996). Development of leader-member exchange: A longitudinal test. Academy of Management Journal, 39, 1538-1567.

Beilock, R., \& Capelle, R. B. (1990). Occupational loyalties among truck drivers. Transportation Journal, 29(3), 20-28.

Blau, P. M. (1964). Exchange and power in social life. New York: John Wiley.

Bradley, J. R., \& Cartwright, S. (2002). Social support, job stress, health, and job satisfaction among nurses in the United Kingdom. International Journal of Stress Management, 9(3), 163-182.

Brouer, R., \& Harris, K. (2007). Dispositional and situational moderators of the relationship between leader-member exchange and work tension. Journal of Applied Social Psychology, 37, 1418-1441.

Bryson, A., Charlwood, A., \& Forth, J. (2006). Worker voice, managerial response and labour productivity: An empirical investigation. Industrial Relations Journal, 37, $438-455$. 


\section{DRIVER TURNOVER AND JOB-INDUCED TENSION}

Bureau of Labor Statistics (2012). National census of occupational injuries in 2011.

Retrieved December $13^{\text {th }}, 2012$ from http://www.bls.gov/news.release.

Burton, J. P., Holtom, B. C., Sablynski, C. J., Mitchell, T. R., \& Lee, T. W. (2010). The buffering effects of job embeddedness on negative shocks. Journal of Vocational Behavior, 76, 42-51.

Cohen-Charash, Y., \& Spector, P. E. (2001). The role of justice in organizations: A metaanalysis. Organizational Behavior and Human Decision Processes, 86, 278-321.

Cogliser, C. C., \& Schriesheim, C. A. (2000). Exploring work unit context and leadermember exchange: A multi-level perspective. Journal of Organizational Behavior, 21, 487-511.

Cooper C. L \& Dewe P. J (2004). Stress: A brief history. Oxford, UK: Blackwell Publishing.

Crissey, J. (2011). Who's in the driver seat? Commercial Carrier Journal. Retrieved April 13, 2013 from http://www.ccjdigital.com/whos-in-the-drivers-seat/

Cropanzano, R., Howes, J. C., Grandey, A. A., \& Toth, P. (1997). The relationship of organizational politics and support to work behaviors, attitudes, and stress. Journal of Organizational Behavior, 18, 159-180.

Cropanzano, R. \& Mitchell, M. S. (2005). Social exchange theory: An interdisciplinary review. Journal of Management, 31, 874-900. 


\section{DRIVER TURNOVER AND JOB-INDUCED TENSION}

da Silva-Júnior, F. P., de Pinho, R. S. N., de Mello, M. T., de Bruin, V. M. S., \& de Bruin, P. F. C. (2009). Risk factors for depression in truck drivers. Social Psychiatry and Psychiatric Epidemiology, 44(2), 125-129.

Dabos, G. E., \& Rousseau, D. M. (2004). Mutuality and reciprocity in the psychological contracts of employees and employers. Journal of Applied Psychology, 89, 52 72.

de Croon, E. M., Sluiter, J. K., Blonk, R. W., Broersen, J. P., \& Frings-Dresen, M. H. (2004). Stressful work, psychological job strain, and turnover: A 2-year prospective cohort study of truck drivers. Journal of Applied Psychology, 89, 442 -454 .

de Croon, E. M., Blonk, R. W., de Zwart, B. C., Frings-Dresen, M. H., \& Broersen, J. P. (2002). Job stress, fatigue, and job dissatisfaction in Dutch lorry drivers: Towards an occupation specific model of job demands and control. Occupational and Environmental Medicine, 59(6), 356-361.

de Pinho R. S. N., da Silva-Junior F. P., Bastos, J. P., Maia, W. S., de Mello, M. T., de Bruin, V. M. de Bruim, P. F. (2006). Hypersomnolence and accidents in truck drivers: A cross-sectional study. Chronobiology International, 23, 963-971. Department of Labor (2010). Women's Bureau. Retrieved April 21, 2013 from http://www.dol.gov/wb/factsheets/nontra2009_txt.htm 


\section{DRIVER TURNOVER AND JOB-INDUCED TENSION}

Dienesch, R. M., \& Liden, R. C. (1986). Leader-member exchange model of leadership: A critique and further development. Academy of Management Review, 11, 618634.

Dillman, D. A. (2011). Improving response to web and mixed-mode surveys. Public Opinion Quarterly, 75(2), 249-269.

Du, C. L., Lin, M. C., Lu, L., \& Tai, J. J. (2011). Correlation of occupational stress index with 24-hour urine cortisol and Serum DHEA sulfate among city bus drivers: A cross-sectional study. Safety and Health at Work, 2, 169-175.

Dupré, K. E., \& Day, A. L. (2007). The effects of supportive management and job quality on the turnover intentions and health of military personnel. Human Resource Management, 46(2), 185-201.

Dulebohn, J. H., Bommer, W. H., Liden, R. C., Brouer, R. L., \& Ferris, G. R. (2012). A meta-analysis of antecedents and consequences of Leader-Member Exchange integrating the past with an eye toward the future. Journal of Management, 38, 1715-1759.

Edmondson, A. (1999). Psychological safety and learning behavior in work teams. Administrative Science Quarterly, 44, 350-383.

Edwards, J. R., \& Lambert, L. S. (2007). Methods for integrating moderation and mediation: A general analytical framework using moderated path analysis. Psychological Methods, 12(1), 1-22. 


\section{DRIVER TURNOVER AND JOB-INDUCED TENSION}

Eisenberger, R., Armeli, S., Rexwinkel, B., Lynch, P. D., \& Rhoades, L. (2001).

Reciprocation of perceived organizational support. Journal of Applied Psychology, $86,42-51$.

Eisenberger, R., Cummings, J., Armeli, S., \& Lynch, P. (1997). Perceived organizational support, discretionary treatment, and job satisfaction. Journal of Applied Psychology, 82, 812-820.

Eisenberger, R., Huntington, R., Hutchison, S., \& Sowa, D. (1986). Perceived organizational support. Journal of Applied Psychology, 71, 500-507.

Emerson, R. M. (1976). Social exchange theory. Annual Review of Sociology, 2, 335-362

Enders, C. K., \& Bandalos D. L. (2001). The relative performance of full information maximum likelihood estimation for missing data in structural equation models. Structural Equation Modeling, 8, 430-457.

Erdogan, B., \& Bauer, T. N. (2010). Differentiated Leader-Member Exchange (LMX): The buffering role of justice climate. Journal of Applied Psychology, 95, 11041120 .

Erdogan, B., Kraimer, M. L., \& Liden, R. C. (2004). Work value congruence and intrinsic career success: The compensatory roles of Leader-Member Exchange and Perceived Organizational Support. Personnel Psychology, 57, 305-332.

Essenberg, B. (2003). Violence and stress at work in the transport sector. International Labour Organisation, Geneva. Retrieved June 1, 2013 from http://siteresources.worldbank.org/INTTSR/Resources/wp205.pdf 


\section{DRIVER TURNOVER AND JOB-INDUCED TENSION}

Farrell, D. (1983). Exit, voice, loyalty, and neglect as responses to job dissatisfaction: A multidimensional scaling study. Academy of Management Journal, 26, 596-607.

Faul, F., Erdfelder, E., Buchner, A., \& Lang, A.-G. (2009). Statistical power analyses using $\mathrm{G}^{*}$ Power 3.1: Tests for correlation and regression analyses. Behavior Research Methods, 41, 1149-1160.

Federal Motor Carrier Safety Administration (FMCSA). (2003). Commercial motor vehicle driver retention and safety. Retrieved February 21, 2012 from http://www.fmcsa.dot.gov/facts-research/research-technology/tech/driverretention-safety.htm.

Ferris, G. R. (1985). Role of leadership in the employee withdrawal process: A constructive replication. Journal of Applied Psychology, 70, 777-781.

Foa, U. G., \& Foa, E. B. (1974). Societal structures of the mind. Springfield, IL: Thomas.

Foa, U. G, \& Foa, E. B. (1980). Resource theory: Interpersonal behavior as exchange. In K. S. Gergen, M. S. Greenberg, \& R. H. Willis (Eds.), Social exchange: Advances in theory and research (pp. 77-94). New York: Plenum Press.

Fournier, P. S., Lamontagne, S., \& Gagnon, J. (2012). Interactions between dispatchers and truck drivers in a high turnover context. Relations Industrielles/Industrial Relations, 67, 263-282.

Freedy, J. R., \& Hobfoll, S. E. (1994). Stress inoculation for reduction of burnout: A conservation of resources approach. Anxiety, Stress and Coping, 6 (4), 311-325. 


\section{DRIVER TURNOVER AND JOB-INDUCED TENSION}

Gaertner, S. (1999). Structural determinants of job satisfaction and organizational commitment in turnover models. Human Resource Management Review, 4, 479493.

Ganster, D. C., Fusilier, M. R., \& Mayes, B. T. (1986). Role of social support in the experience of stress at work. Journal of Applied Psychology, 71, 102 -110.

Gerstner, C. R., \& Day, D. V. (1997). Meta-analytic review of Leader-Member Exchange theory: Correlates and construct issues. Journal of Applied Psychology, 82, $827-844$.

Gouldner, A. W. (1960). The norm of reciprocity: A preliminary statement. American Sociological Review, 161-178.

Graen, G. B. (1976). Role-making processes within complex organizations. In M. D. Dunnette (Ed.), Handbook of industrial and organizational psychology (pp. 12011245). Chicago: Rand McNally.

Graen, G. B., Liden, R. C., \& Hoel, W. (1982). Role of leadership in the employee withdrawal process. Journal of Applied Psychology, 67, 868 - 872.

Graen, G. B., \& Scandura, T. A. (1987). Toward a psychology of dyadic organizing. Research in Organizational Behavior, 9, 175-208.

Graen, G. B., \& Uhl-Bien, M. (1995). Relationship-based approach to leadership: Development of leader-member exchange (LMX) theory of leadership over 25 years: Applying a multi-level multi-domain perspective. The Leadership Quarterly, 6, 219-247. 


\section{DRIVER TURNOVER AND JOB-INDUCED TENSION}

Grandey, A. A., \& Cropanzano, R. (1999). The conservation of resources model applied to work-family conflict and strain. Journal of Vocational Behavior, 54, 350-370.

Griffeth, R. W., Hom, P. M., \& Gaertner, S. (2000). A meta-analysis of antecedents and correlated of employee turnover: Update, moderator tests, and research implications for the next millennium. Journal of Management, 26, 463-488.

Griffin, G., \& Kalnbach, L. (2002). Predicting and classifying voluntary turnover decisions for truckload drivers (No. MPC Report No. 02-135).

Ghiselli, E. E. (1974). Some perspectives for industrial psychology. American Psychologist, 29(2), $80-87$.

Halbesleben, J. R. (2006). Sources of social support and burnout: a meta-analytic test of the conservation of resources model. Journal of Applied Psychology, 91, 1134 1145

Harris, K. J., Harris, R. B., \& Brouer, R. L. (2009). LMX and subordinate political skill: Direct and interactive effects on turnover intentions and job satisfaction. Journal of Applied Social Psychology, 39, 2373-2395.

Harris, K. J., \& Kacmar, K. M. (2006). Too much of a good thing: The curvilinear effect of leader-member exchange on stress. The Journal of Social Psychology, 146(1), $65-84$

Harris, K. J., Kacmar, K. M., \& Witt, L. A. (2005). An examination of the curvilinear relationship between leader-member exchange and intent to turnover. Journal of Organizational Behavior, 26, 363-378. 


\section{DRIVER TURNOVER AND JOB-INDUCED TENSION}

Harris, K. J., Wheeler, A. R., \& Kacmar, K. M. (2009). Leader-member exchange and empowerment: Direct and interactive effects on job satisfaction, turnover intentions, and performance. The Leadership Quarterly, 20, 371-382.

Harris, K. J., Wheeler, A. R., \& Kacmar, K. M. (2011). The mediating role of organizational job embeddedness in the LMX-outcomes relationships. Leadership Quarterly, 22, 271-281.

Harvey, P., Harris, R. B., Harris, K. J., \& Wheeler, A. R. (2007). Attenuating the effects of social stress: The impact of political skill. Journal of Occupational Health Psychology, 12, $105-115$.

Hedberg, G. E., \& Langendoen, S. M. (1989). Factors influencing the turnover of Swedish professional drivers. Scandinavian Journal of Public Health, 17(3), 231237.

Hirschman, A. 0. (1970). Exit, voice and loyalty responses to declines in firms, organizations and states. Cambridge, MA: Harvard University Press.

Hobfoll, S. E. (1989). Conservation of resources: A new attempt at conceptualizing stress. American Psychologist, 44, 513 - 524.

Hobfoll, S. E. (2001). The influence of culture, community, and the nested-self in the stress process: advancing conservation of resources theory. Applied Psychology, 50(3), 337-421.

Hochwarter, W. A., \& Byrne, Z. S. (2005). LMX and job tension: Linear and non-linear effects and affectivity. Journal of Business and Psychology, 19, 505-520 


\section{DRIVER TURNOVER AND JOB-INDUCED TENSION}

Hofmann, D. A., \& Morgeson, F. P. (1999). Safety-related behavior as a social exchange: The role of perceived organizational support and leader-member exchange. Journal of Applied Psychology, 84, 286-296.

Hofmann, D. A., Morgeson, F. P., \& Gerras, S. J. (2003). Climate as a moderator of the relationship between leader-member exchange and content specific citizenship: Safety climate as an exemplar. Journal of Applied Psychology, 88, 170 -178.

Hoffmann, E. A. (2006). Exit and voice: Organizational loyalty and dispute resolution strategies. Social Forces, 84, 2313-2330.

Holtom, B. C., Mitchell, T. R., Lee, T. W., \& Eberly, M. B. (2008). Turnover and retention research: A glance at the past, a closer review of the present, and a venture into the future. The Academy of Management Annals, 2, 231-274.

Hom, P. W. \& Griffeth, R. W. (1995). Employee turnover. Cincinnati: South-Western.

Hooper, D. T., \& Martin, R. (2008). Beyond personal leader-member exchange (LMX) quality: The effects of perceived LMX variability on employee reactions. The Leadership Quarterly, 19, 20-30.

Horne, J., \& Reyner, L. (1999). Vehicle accidents related to sleep: A review. Occupational and Environmental Medicine, 56(5), 289-294.

House, R. J., \& Rizzo, J. R. (1972). Role conflict and ambiguity as critical variables in a model of organizational behavior. Organizational Behavior and Human Performance, 7, 467-505. 


\section{DRIVER TURNOVER AND JOB-INDUCED TENSION}

Howell, D. C. (2010). Statistical methods for psychology. Belmont, CA: Wadsforth, Cengage Learning.

Ilies, R., Nahrgang, J. D., \& Morgeson, F. P. (2007). Leader-member exchange and citizenship behaviors: A meta-analysis. Journal of Applied Psychology, 92, 269277.

Jamal, M. (1990). Relationship of job stress and Type-A behavior to employees' job satisfaction, organizational commitment, psychosomatic health problems, and turnover motivation. Human Relations, 43, 727-738.

Jawahar, I. M., Stone, T. H., \& Kisamore, J. L. (2007). Role conflict and burnout: The direct and moderating effects of political skill and perceived organizational support on burnout dimensions. International Journal of Stress Management, 14, 142-159.

Jex, S. M., \& Beehr, T. A. (1991). Emerging theoretical and methodological issues in the study of work-related stress. Research in Personnel and Human Resources Management, $9(31), 1-365$.

Jones, B., Flynn, D. B., \& Kelloway, E. K. (1995). Perception of support from the organization in relation to work stress, satisfaction, and commitment. In S. L. Sauter, \& L. R. Murphy (Eds.), Organizational risk factors for job stress (pp. 4152). Washington, DC: American Psychological Association.

Judge, T. A., \& Watanabe, S. (1995). Is the past prologue?: A test of Ghiselli's hobo syndrome. Journal of Management, 21, 211-229. 


\section{DRIVER TURNOVER AND JOB-INDUCED TENSION}

Kahn, R. L., Wolfe, D. M., Quinn, R. P., Snoek, J. D., \& Rosenthal, R. A. (1964). Organizational stress: Studies in role conflict and ambiguity. Oxford: Wiley.

Kamdar, D., \& Van Dyne, L. (2007). The joint effects of personality and workplace social exchange relationships in predicting task performance and citizenship performance. Journal of Applied Psychology, 92, 1286-1298.

Kang, B., Twigg, N. W., \& Hertzman, J. (2010). An examination of social support and social identity factors and their relationship to certified chefs' burnout. International Journal of Hospitality Management, 29(1), 168-176.

Keller, S. B. (2002). Driver relationships with customers and driver turnover: key mediating variables affecting driver performance in the field. Journal of Business Logistics, 23, 39-64.

Keller, S. B., \& Ozment, J. (1999a). Managing driver retention: Effects of the dispatcher. Journal of Business Logistics, 20, 97-120.

Keller, S. B., \& Ozment, J. (1999b). Exploring dispatcher characteristics and their effect on driver retention. Transportation Journal, 39(1), 20-33.

Kim, B. P., Lee, G., \& Carlson, K. D. (2010). An examination of the nature of the relationship between Leader-Member-Exchange (LMX) and turnover intent at different organizational levels. International Journal of Hospitality Management, $29(4), 591-597$. 


\section{DRIVER TURNOVER AND JOB-INDUCED TENSION}

Lagace, R. R., Castlebeny, S. B., \& Ridnour, R. E. (1993). An exploratory salesforce study of the relationship between leader-member exchange and motivation, role stress, and manager evaluation. Journal of Applied Business Research, 9, 110-119.

Lapierre, L. M., \& Allen, T. D. (2006). Work-supportive family, family-supportive supervision, use of organizational benefits, and problem-focused coping: Implications for work-family conflict and employee well-being. Journal of Occupational Health Psychology, 11, 169-181.

Lawrence, E. R., \& Kacmar, K. M. (2012). Leader-Member Exchange and stress: The mediating role of job involvement and role conflict. Retrieved July 30, 2013 from http://www.ibam.com/pubs/jbam/articles/vol14/Article3.pdf

Lazarus, R. S., \& Folkman. S. (1984). Stress, appraisal, and coping. New York: Springer.

Lee, T. W., \& Maurer, S. D. (1997). The retention of knowledge workers with the unfolding model of voluntary turnover. Human Resource Management Review, 7, 247-275.

Lee, T. W., \& Mitchell, T. R. (1994). An alternative approach: The unfolding model of voluntary employee turnover. Academy of Management Review, 19, 51-89.

Lee, T. W., Mitchell, T. R., Sablynski, C. J., Burton, J. P., \& Holtom, B. C. (2004). The effects of job embeddedness on organizational citizenship, job performance, volitional absences, and voluntary turnover. Academy of Management Journal, 47, 711-722. 


\section{DRIVER TURNOVER AND JOB-INDUCED TENSION}

LeMay, S. A., Taylor, G. S., \& Turner, G. B. (1993). Driver turnover and management policy: A survey of truckload irregular route motor carriers. Transportation Journal, 33(2), 15-21.

Liden, R. C., Erdogan, B., Wayne, S. J., \& Sparrowe, R. T. (2006). Leader-member exchange, differentiation, and task interdependence: Implications for individual and group performance. Journal of Organizational Behavior, 27, 723-746.

Liden, R. C., \& Graen, G. B. (1980). Generalizability of the vertical dyad linkage model of leadership. Academy of Management Journal, 23, 451-465.

Liden, R. C., \& Maslyn, J. M. (1998). Multidimensionality of Leader-Member Exchange: An empirical assessment through scale development. Journal of Management, 24, 43-72.

Liden, R. C., Sparrowe, R. T., \& Wayne, S. J. (1997). Leader-Member Exchange theory: The past and potential for the future. In G. Ferris (Ed.), Research in personnel and human resource management (Vol. 15, pp. 47-119). Greenwich, CT: JAI Press.

Liden, R. C., Wayne, S. J., \& Stilwell, D. (1993). A longitudinal study on the early development of leader-member exchanges. Journal of Applied Psychology, 78, $662-674$.

Long, J. S. (1997). Regression models for categorical and limited dependent variables (Vol. 7). Thousand Oaks, CA: Sage.

Maertz, C. P., \& Campion, M. A. (1998). Turnover. International Review of Industrial and Organizational Psychology, 13, 49-82. 


\section{DRIVER TURNOVER AND JOB-INDUCED TENSION}

Maertz, C. P., Griffeth, R. W., Campbell, N. S., \& Allen, D. G. (2007). The effects of perceived organizational support and perceived supervisor support on employee turnover. Journal of Organizational Behavior, 28, 1059-1075.

March, J. G., \& Simon, H. A. (1958). Organizations. New York, NY: Wiley.

Maslyn, J. M., \& Uhl-Bien, M. (2001). Leader-member exchange and its dimensions: Effects of self-effort and other's effort on relationship quality. Journal of Applied Psychology, 86, 697-708.

Masterson, S. S. (2001). A trickle-down model of organizational justice: relating employees' and customers' perceptions of and reactions to fairness. Journal of Applied Psychology, 86, 594 - 604.

Meeker, B. F. (1971). Decisions and exchange. American Sociological Review, 485-495.

Meyer, J. P., Allen, N. J., \& Smith, C. A. (1993). Commitment to organizations and occupations: Extension and test of a three-component conceptualization. Journal of Applied Psychology, 78, 538-551.

Meyer, J. P., \& Herscovitch, L. (2001). Commitment in the workplace: Toward a general model. Human Resource Management Review, 11(3), 299-326.

Min, H., \& Lambert, T. (2002). Truck driver shortage revisited. Transportation Journal, 2, 5-16.

Mitchell, T. R., Holtom, B. C., Lee, T. W., Sablynski, C. J., \& Erez, M. (2001). Why people stay: Using job embeddedness to predict voluntary turnover. Academy of Management Journal, 44, 1102-1121. 


\section{DRIVER TURNOVER AND JOB-INDUCED TENSION}

Molm, L. D. (2001). Theories of social exchange and exchange networks. In G. Ritzer \& B. Smart (Eds.), Handbook of social theory (pp. 260-272). London: Sage.

Molm, L. D. (2003). Theoretical comparisons of forms of exchange. Sociological Theory, 21(1), 1-17.

Morgan-Lopez, A. A., \& MacKinnon, D. P. (2006). Demonstration and evaluation of a method for assessing mediated moderation. Behavior Research Methods, 38, 7787.

Moreno, C. R., Carvalho, F. A., Lorenzi, C., Matuzaki, L. S., Prezotti, S., Bighetti, P., Louzada, F. M., \& Lorenzi-Filho, G. (2004). High risk for obstructive sleep apnea in truck drivers estimated by the Berlin questionnaire: Prevalence and associated factors. Chronobiology International, 21, 871-879.

Morrow, P. C., Suzuki, Y., Crum, M. R., Ruben, R., \& Pautsch, G. (2005). The role of leader-member exchange in high turnover work environments. Journal of Managerial Psychology, 20, 681-694.

Mossholder, K. W., Settoon, R. P., \& Henagan, S. C. (2005). A relational perspective on turnover: Examining structural, attitudinal, and behavioral predictors. Academy of Management Journal, 48, 607-618.

Muller, D., Judd, C. M., \& Yzerbyt, V. Y. (2005). When moderation is mediated and mediation is moderated. Journal of Personality and Social Psychology, 89, 852863. 


\section{DRIVER TURNOVER AND JOB-INDUCED TENSION}

Nishii, L. H., \& Mayer, D. M. (2009). Do inclusive leaders help to reduce turnover in diverse groups? The moderating role of leader-member exchange in the diversity to turnover relationship. Journal of Applied Psychology, 94, 1412-1426.

Ohly, S., Sonnentag, S., \& Pluntke, F. (2006). Routinization, work characteristics and their relationships with creative and proactive behaviors. Journal of Organizational Behavior, 27, 257-279.

Olson, R., Anger, W. K., Elliot, D. L., Wipfli, B., \& Gray, M. (2009). A new health promotion model for lone workers: Results of the Safety \& Health Involvement for Truckers (SHIFT) pilot study. Journal of Occupational and Environmental Medicine, 51, 1233-1246.

Ozment, J., \& Keller, S. (1999). Exploring dispatcher communication effectiveness: Implications for retaining drivers in the trucking industry. Journal of Managerial Issues, 11, 94-109.

Paillé, P., Fournier, P. S., \& Lamontagne, S. (2011). Relationships between commitments to the organization, the superior and the colleagues, and the intention to leave among truckers. International Journal of Organizational Analysis, 19(2), 92-108.

Parasuraman, S., Greenhaus, J. H., \& Granrose, C. S. (1992). Role stressors, social support, and well-being among two-career couples. Journal of Organizational Behavior, 13, 339-356. 


\section{DRIVER TURNOVER AND JOB-INDUCED TENSION}

Peiró, J. M., Romá, V. G., Ramos, J., \& Zornoza, A. (1996). Relationships between leadership and professionals' job attitudes and perceptions: Comparison of two leadership models. Work \& Stress, 10, 195-208.

Pitariu, A. H., \& Ployhart, R. E. (2010). Explaining change: Theorizing and testing dynamic mediated longitudinal relationships. Journal of Management, 36, 405429.

Ployhart, R. E., \& Vandenberg, R. J. (2010). Longitudinal research: The theory, design, and analysis of change. Journal of Management, 36, 94-120.

Premeaux, S. F., Adkins, C. L., \& Mossholder, K. W. (2007). Balancing work and family: a field study of multi-dimensional, multi-role work-family conflict. Journal of Organizational Behavior, 28(6), 705-727.

Richard, M. D., LeMay, S. A., \& Taylor, G. S. (1995). A factor-analytic logit approach to truck driver turnover. Journal of Business Logistics, 16, 281-281.

Richard, M. D., LeMay, S. A., Taylor, G. S., \& Turner, G. B. (1994). A canonical correlation analysis of extrinsic satisfaction in a transportation setting. Logistics and Transportation Review, 30(4), 327-348.

Ring, J. K. (2010). The effect of perceived organizational support and safety climate on voluntary turnover in the transportation industry. International Journal of Business Research and Management, 1 (3), 156-168.

Rhoades, L., \& Eisenberger, R. (2002). Perceived organizational support: A review of the literature. Journal of Applied Psychology, 87, 698 - 714. 


\section{DRIVER TURNOVER AND JOB-INDUCED TENSION}

Robinson, C. F., \& Burnett, C. A. (2005). Truck drivers and heart disease in the United States, 1979-1990. American Journal of Industrial Medicine, 47(2), 113-119.

Rockstuhl, T., Dulebohn, J. H., Ang, S., \& Shore, L. M. (2012). Leader-member exchange (LMX) and culture: A meta-analysis of correlates of LMX across 23 countries. Journal of Applied Psychology, 97, 1097-1130

Rodriguez, J., Kosir, M., Lantz, B., Griffin, G., \& Glatt, J. (2000). The cost of truckload driver turnover. Upper Great Plains Transportation Institute. Retrieved June 20, 2013 from http://www.ugpti.org/

Rupp, D. E., \& Cropanzano, R. (2002). The mediating effects of social exchange relationships in predicting workplace outcomes from multifoci organizational justice. Organizational Behavior and Human Decision Processes, 89, 925-946.

Rusbult, C. E., Farrell, D., Rogers, G., \& Mainous, A. G. (1988). Impact of exchange variables on exit, voice, loyalty, and neglect: An integrative model of responses to declining job satisfaction. Academy of Management Journal, 31, 599-627.

Saltzman, G. M., \& Belzer, M. H. (2007). Truck Driver Occupational Safety and Health: 2003 Conference Report and Selective Literature Review (No. DHHS (NIOSH) Publication No. 2007-120).

Saunders, D. M., Sheppard, B. H., Knight, V., \& Roth, J. (1992). Employee voice to supervisors. Employee Responsibilities and Rights Journal, 5, 241-259.

Scandura, T. A. (1999). Rethinking leader-member exchange: An organizational justice perspective. The Leadership Quarterly, 10, 25-40. 


\section{DRIVER TURNOVER AND JOB-INDUCED TENSION}

Scandura, T. A., \& Graen, G. B. (1984). Moderating effects of initial leader-member exchange status on the effects of a leadership intervention. Journal of Applied Psychology, 69, 428-436.

Shattell, M., Apostolopoulos, Y., Sönmez, S., \& Griffin, M. (2010). Occupational stressors and the mental health of truckers. Issues in mental health nursing, 31, $561-568$.

Shaw, J., Delery, J., Jenkins, G., \& Gupta, N. (1998). An organization-level analysis of voluntary and involuntary turnover. Academy of Management Journal, 41, 511525.

Sherman, K. E., Kennedy, D. M., Woodard, M. S., \& McComb, S. A. (2012). Examining the "exchange" in leader-member exchange. Journal of Leadership \& Organizational Studies, 19, 407-423.

Snyder, R. A., \& Bruning, N. S. (1985). Quality of vertical dyad linkages: Congruence of supervisor and subordinate competence and role stress as explanatory variables. Group \& Organization Management, 10, 81-94.

Spielberger, C. D., Gorsuch, R. L., Lushene, R., Vagg, P. R., \& Jacobs, G. A. (1983). Manual for the State-Trait Anxiety Inventory. Palo Alto, CA: Consulting Psychologists Press.

Sobel, M. E. (1982). Asymptotic confidence intervals for indirect effects in structural equation models. In S. Leinhardt (Ed.), Sociological methodology (pp. 290-212). San Francisco, CA: Jossey-Bass. 


\section{DRIVER TURNOVER AND JOB-INDUCED TENSION}

Stephenson, F. J., \& Fox, R. J. (1996). Driver retention solutions: Strategies for for-hire truckload employee drivers. Transportation Journal, 35, 12-24.

Suzuki, Y., Crum, M. R., \& Pautsch, G. R. (2009). Predicting truck driver turnover. Transportation Research Part E: Logistics and Transportation Review, 45, 538550.

Tabachnick, B. G., \& Fidell, L. S. (2007). Using multivariate statistics (5th ed.). Boston, MA: Pearson Education.

Taylor, G. S. (1991). Using performance appraisals of dispatchers to reduce driver turnover. Transportation Journal, 30(4), 49-55.

Taylor, S. L., \& Cosenza, R. M. (1998). Truck driver turnover: An internal marketing perspective. Journal of Transportation Management, 10, 20-32.

Tyler, T. R., \& Blader, S. L. (2003). The group engagement model: Procedural justice, social identity, and cooperative behavior. Personality and Social Psychology Review, 7, 349-361.

Thibaut J. W., \& Kelley, H. H. (1959). The social psychology of groups. New York: Wiley.

Thomas, C. H., \& Lankau, M. J. (2009). Preventing burnout: The effects of LMX and mentoring on socialization, role stress, and burnout. Human Resource Management, 48, 417-432.

Treadway, D. C., Ferris, G. R., Hochwarter, W., Perrewé, P., Witt, L. A., \& Goodman, J. M. (2005). The role of age in the perceptions of politics--job performance 


\section{DRIVER TURNOVER AND JOB-INDUCED TENSION}

relationship: A three-study constructive replication. Journal of Applied Psychology, 90, 872 - 881.

Turnley, W. H., \& Feldman, D. C. (1999). The impact of psychological contract violations on exit, voice, loyalty, and neglect. Human Relations, 52, 895-922.

Van Dyne, L., Ang, S., \& Botero, I. C. (2003). Conceptualizing employee silence and employee voice as multidimensional constructs. Journal of Management Studies, 40, 1359-1392.

Van Dyne, L., \& LePine, J. A. (1998). Helping and voice extra-role behaviors: Evidence of construct and predictive validity. Academy of Management Journal, 41, 108119.

Vecchio, R. P. (1997). Are you in or out with your boss? In R. P. Vecchio (Ed.), Leadership: Understanding the dynamics of power and influence in organizations (pp. 274-277). South Bend, IN: University of Notre Dame Press.

Viswesvaran, C., Sanchez, J. I., \& Fisher, J. (1999). The role of social support in the process of work stress: A meta-analysis. Journal of Vocational Behavior, 54, 314334.

Weber, T. (2011). Exit, voice, and cyclicality: A micrologic of midterm effects in European parliament elections. American Journal of Political Science, 55, 907922. 


\section{DRIVER TURNOVER AND JOB-INDUCED TENSION}

Wheeler, A. R., Harris, K. J., \& Harvey, P. (2010). Moderating and mediating the HRM effectiveness - intent to turnover relationship: The roles of supervisors and job embeddedness. Journal of Managerial Issues, 22(2), 182 - 196.

Whitaker, B. (2010). Driver turnover: Costs, causes, and solutions. Retrieved on July 25, 2013 from

http://www.avatarms.com/whitepapers/Driver\%20Turnover\%20Costs, \%20Causes \%20And $\% 20$ Solutions.pdf

Wiegand, D. M., Hanowski, R. J., \& McDonald, S. E. (2009). Commercial drivers' health: A naturalistic study of body mass index, fatigue, and involvement in safety-critical events. Traffic injury prevention, 10(6), 573-579.

Williams, Z., Garver, M. S., \& Taylor, G. S. (2011). Understanding truck driver needbased segments: Creating a strategy for retention. Journal of Business Logistics, 32, 194-98.

Withey, M. J., \& Cooper, W. H. (1989). Predicting exit, voice, loyalty, and neglect. Administrative Science Quarterly, 34, 521-539

Wright, T. A., \& Cropanzano, R. (1998). Emotional exhaustion as a predictor of job performance and voluntary turnover. Journal of Applied Psychology, 83, $486-$ 493.

Wright, L., \& Quinlan, M. (2008). Remuneration and safety in the Australian heavy vehicle industry: A review undertaken for the National Transport Commission, October 2008, Report prepared for the National Transport Commission, 


\section{DRIVER TURNOVER AND JOB-INDUCED TENSION}

Melbourne. Retrieved July 17, 2013 from

https://eprints.mdx.ac.uk/7206/1/RemunSafetyAustHVIndustryNov08.pdf 


\section{DRIVER TURNOVER AND JOB-INDUCED TENSION}

Appendix A

Items for the composite variable dispatcher communication effectiveness

Dispatcher communication effectiveness - 5 items, modified scale

1. My dispatcher acts like it is important to get feedback from drivers.

2. Drivers can freely exchange opinions with dispatchers.

3. Dispatchers always encourage drivers to bring new information to their attention even when the new information may be bad news.

4. When drivers complain about something beyond the dispatcher's control, the complaint is passed to someone who has control.

5. My dispatcher acts as if it is very important to respond to every driver complaint.

Dispatcher sensitivity to voice - 4 items, Ozment \& Keller (1999a, 1999b)

1. My dispatcher acts like it is important to get feedback from drivers.

2. Drivers can freely exchange opinions with dispatchers.

3. Dispatchers always encourage drivers to let them know when anything goes wrong on the job.

4. Dispatchers always encourage drivers to bring new information to their attention even when the new information may be bad news.

Dispatcher responsiveness- 5 items, Keller (2002)

1. When drivers complain about something beyond the dispatcher's control, the complaint is passed to someone who has control.

2. The job of the dispatcher is not too demanding in that they have time to address every driver complaint they hear.

3. My dispatcher acts as if it is very important to respond to every driver complaint.

4. My dispatcher's actions are very important for correcting all complaints raised by their drivers.

5. Dispatchers always have the opportunity to respond to every complaint raised by their drivers.

Note: Items in italics are original items removed from modified scale. Bolded items are the retained items. 


\section{DRIVER TURNOVER AND JOB-INDUCED TENSION}

\section{Appendix B}

Survey Items

Instructions: Please read each statement carefully and indicate the extent to which you AGREE with each statement by circling the appropriate number following each statement using the following 1 to 7 scale. Your answers will remain confidential.

All responses were on a 1-7 scale with $1=$ strongly disagree to $7=$ strongly agree

\section{Perceived Organizational Support - 8 items, Eisenberger et al. (1986)}

Market Transport values my contribution to its well-being.

Market Transport appreciates any extra effort from me.

Market Transport would listen to any complaint from me.

Market Transport really cares about my well-being.

If I did the best job possible, Market Transport would notice.

Market Transport cares about my general satisfaction at work.

Market Transport shows concern for me.

Market Transport takes pride in my accomplishments at work.

Job Induced tension - 7 items, House \& Rizzo (1972)

My job tends to directly affect my health.

I work under a great deal of tension.

I have felt fidgety or nervous as a result of my job.

If I had a different job, my health would probably improve.

Problems associated with my job have kept me awake at night.

I have felt nervous before attending meetings in the company.

\section{Dispatcher sensitivity to voice -4 items, Keller \& Ozment (1999)}

My dispatcher acts like it is important to get feedback from drivers. 


\section{DRIVER TURNOVER AND JOB-INDUCED TENSION}

Drivers can freely exchange opinions with dispatchers.

Dispatchers always encourage drivers to let them know when anything goes wrong on the job.

Dispatchers always encourage drivers to bring new information to their attention even when the new information may be bad news.

\section{Dispatcher responsiveness- 5 items, Keller (2002)}

When drivers complain about something beyond the dispatcher's control, the complaint is passed to someone who has control.

The job of the dispatcher is not too demanding in that they have time to address every driver complaint they hear.

My dispatcher acts as if it is very important to respond to every driver complaint.

My dispatcher's actions are very important for correcting all complaints raised by their drivers.

Dispatchers always have the opportunity to respond to every complaint raised by their drivers.

\section{Leader-Member Exchange - 7, Scandura \& Graen (1984)}

\section{Please place the name and title of your supervisor below}

Name:

Title:

Regardless of how much power he/she has built into his/her position, my supervisor would be personally inclined to use his/her power to help me solve problems in my work.

I can count on my supervisor to "bail me out" even at his/her own expense, when I really need it.

My supervisor understands my problems and needs.

My supervisor recognizes my potential.

My supervisor has enough confidence in me that he/she would defend and justify my decisions if I were not present to do so.

I usually know where I stand with my supervisor.

My working relationship with my supervisor is effective.

\section{In general, I feel my health is...(please circle)}

Excellent Very Good Good Fair Poor




\section{DRIVER TURNOVER AND JOB-INDUCED TENSION}

How many years have you worked as a commercial truck driver?

How many different trucking employers have you had in the past three years?

About how many miles did you drive for work last year?

About how many miles is your typical run or dispatch?

How many hours do you usually drive in 1 week (7 days)?

On your typical dispatch, how many days are you away from home?

What is the name of the dispatcher you work with most routinely?

What percentage of your time working is spent working with this dispatcher?

If you work with another dispatcher routinely, please write their name here.

What percentage of your time working is spent interacting with this other dispatcher?

What is your gender?

What is your relationship status?

Do you have any children living at home?

If yes, how many? What are their ages?

What is the highest grade of school or year of college you completed?

What is your ethnic background?

White (Caucasian) Hispanic/Latino African-American Asian-American Native American/Pacific Islander Other (please specify) 